\title{
The impact of daily temperature on renal disease incidence: an ecological study
}

\author{
Matthew Borg ${ }^{1}$, Peng Bi ${ }^{1 *} \mathbb{B}$, Monika Nitschke ${ }^{2}$, Susan Williams ${ }^{1}$ and Stephen McDonald ${ }^{3}$
}

\begin{abstract}
Background: Extremely high temperatures over many consecutive days have been linked to an increase in renal disease in several cities. This is becoming increasingly relevant with heatwaves becoming longer, more intense, and more frequent with climate change. This study aimed to extend the known relationship between daily temperature and kidney disease to include the incidence of eight temperature-prone specific renal disease categories - total renal disease, urolithiasis, renal failure, acute kidney injury (AKI), chronic kidney disease (CKD), urinary tract infections (UTIs), lower urinary tract infections (LUTIs) and pyelonephritis.

Methods: Daily data was acquired for maximum, minimum and average temperature over the period of 1 July 2003 to 31 March 2014 during the warm season (October to March) in Adelaide, South Australia. Data for daily admissions to all metropolitan hospitals for renal disease, including 83,519 emergency department admissions and 42,957 inpatient admissions, was also obtained. Renal outcomes were analyzed using time-stratified negative binomial regression models, with the results aggregated by day. Incidence rate ratios (IRR) and 95\% confidence intervals $(\mathrm{Cl})$ were estimated for associations between the number of admissions and daily temperature.

Results: Increases in daily temperature per $1{ }^{\circ} \mathrm{C}$ were associated with an increased incidence for all renal disease categories except for pyelonephritis. Minimum temperature was associated with the greatest increase in renal disease followed by average temperature and then maximum temperature. A $1^{\circ} \mathrm{C}$ increase in daily minimum temperature was associated with an increase in daily emergency department admissions for AKI (IRR 1.037, 95\% Cl: 1.026-1.048), renal failure (IRR 1.030, 95\% Cl: 1.022-1.039), CKD (IRR 1.017, 95\% Cl: 1.001-1.033) urolithiasis (IRR 1.015, 95\% Cl: 1.010-1.020), total renal disease (IRR 1.009, 95\% Cl: 1.006-1.011), UTIs (IRR 1.004, 95\% Cl: 1.000-1.007) and LUTIs (IRR 1.003, 95\% Cl: 1.000-1.006).

Conclusions: An increased frequency of renal disease, including urolithiasis, acute kidney injury and urinary tract infections, is predicted with increasing temperatures from climate change. These results have clinical and public health implications for the management of renal diseases and demand tailored health services. Future research is warranted to analyze individual renal diseases with more comprehensive information regarding renal risk factors, and studies examining mortality for specific renal diseases.
\end{abstract}

Keywords: Temperature, Heat, Renal disease, Urolithiasis, Acute kidney injury, Renal failure, Chronic kidney disease, Urinary tract infections, Lower urinary tract infections, Pyelonephritis

\section{Background}

Excessive seasonal temperatures predispose to adverse heatrelated human morbidity in multiple organ systems [1, 2]. These health effects have mostly been investigated with regards to cardiovascular, respiratory and well-known heatrelated diseases [3], but have also been observed for renal disease $[1,3-6]$. This is becoming increasingly more relevant

\footnotetext{
* Correspondence: peng.bi@adelaide.edu.au

${ }^{1}$ School of Public Health, University of Adelaide, Adelaide, South Australia

5005, Australia

Full list of author information is available at the end of the article
}

due to the impact of climate change [7-9]. Two studies in Adelaide, Australia, showed increased admissions for renal disease during heatwaves through all ages, by $10 \%$ and $13 \%$, respectively [10, 11], and another study in Adelaide also identified an association between temperature and renal disease [12]. International studies have shown similar results $[3,13-15]$. Studies in the United States of America (USA) linked incremental rises in same-day apparent temperatures to an increased occurrence of renal disease and acute kidney injury (AKI, also known as acute renal failure) $[1,13]$. 
In many cities, high temperatures have been linked to an increased occurrence of AKI [3, 11, 13, 15-17] and chronic kidney disease (CKD, also known as chronic renal failure) $[18,19]$. A study in Sydney, Australia, reported that the incidence of AKI and renal failure (AKI and CKD combined) increased if the daily temperature was above the 95th percentile range for one day, and this further increased if the high temperature persisted for three days [4]. AKI and urolithiasis also predispose to chronic kidney disease, though paradoxically, CKD can help prevent urolithiasis due to a disease-associated decrease in urinary calcium secretion [20, 21].

The risk of renal colic (pain due to urolithiasis) increases with higher daily temperature [22-26]. Studies in Australia and New Zealand have demonstrated seasonal variation in the incidence of renal colic, highest in summer and autumn $[8,27,28]$. A USA study also reported that the incidence of urolithiasis is greatest in warmer areas, specifically uric acid and calcium stones [14]. Even though urinary stones usually form over months [25, 29], investigations in Sydney and the USA showed the risk for urolithiasis was highest $\leq 3$ days after exposure to high ambient temperatures, with a peak at day one $[4,13,30]$. The risk can be increased for the next 20 days as well [25]. It has been suggested that the incidence and prevalence of urolithiasis are increasing due to climate change $[14,31]$.

Research on the relationship between ambient air temperature and urinary tract infections (UTIs) is inconclusive. UTIs include pyelonephritis (infection of renal pelvis, calyces and/or tissue) and lower urinary tract infections (LUTIs) which are UTIs occurring below the renal pelvis. One trial in the USA found a positive association between hospitalizations during heatwaves and primary diagnoses for UTIs and septicemia [3]. Other studies have not found such association [4]. Hospitalizations and ED admissions for nephritis increased significantly during the 2006 California heatwave [17].

Whilst studies in different countries have examined these various renal outcomes, their results might not be generalizable to countries with different climate and population characteristics [32, 33]. A previous study in Adelaide, Australia, found increased incidence of AKI and renal disease during heatwaves [11]. The present study extends those findings by considering a wider range of specific renal diseases and their associations with temperature. It is the first study to investigate the link between heat exposure and urolithiasis, UTIs and CKD in an Australian population. The results will have clinical and public health implications for the management of renal diseases in a temperate climate region.

\section{Methods}

\section{Aim and design}

To examine if the incidence of eight temperature-prone specific renal disease categories in metropolitan Adelaide would increase in relation to a $1^{\circ} \mathrm{C}$ increase in daily dry bulb temperature. This study is an ecological study with a time-series approach.

\section{Setting}

Adelaide's predicted population in June 2016 was 1.32 million [34]. With a total land area of $983,482 \mathrm{~km}^{2}$ [35], the state has a semi-arid climate with mild winters and dry, hot summers with cool nights [36]. Adelaide recently experienced multiple heatwaves including during March 2008, January to February 2009, November 2009 and during the summer of 2013-2014 [37]. 2013 was the warmest year on record for Adelaide, and 2015 was the second warmest [38]. Increased frequency, intensity and duration of hot days are predicted in Australia with climate change [39].

\section{Data collection}

Hospital inpatient and ED admissions data for a range of International Classification of Diseases, 10th revision (ICD10) classification codes were acquired from the South Australian Department of Health for the period spanning 1 July 2003 to 31 March 2014. Data represented admissions to hospitals within the Adelaide metropolitan region. Elective admissions (patient did not require admission within $24 \mathrm{~h}$ ) were excluded from the data because emergency admissions (patient required admission within 24 h) are more likely to reflect the acute effects of heat exposure.

Daily meteorological data for maximum and minimum dry bulb temperature were obtained from the Bureau of Meteorology from a monitoring station in Kent Town (station number 023090) [37], Adelaide. Data from this station is representative of climate across the Adelaide metropolitan area. Because this data only represented the metropolitan area, admission of patients living in rural areas were excluded from this study. Daily maximum and minimum temperatures were recorded at $9 \mathrm{am}$; the data is included in Additional file 1. The highest temperature recorded in the $24 \mathrm{~h}$ prior to $9 \mathrm{am}$ is recorded as the maximum daily temperature for the previous day which usually occurs in the afternoon, while the lowest temperature occurring in the same $24 \mathrm{~h}$ is recorded as the daily minimum temperature for the current day which usually occurs overnight or near dawn [40]. The average daily temperature was calculated from these daily maximum and minimum temperatures. Descriptive statistics of the temperature data is included in Table 1.

Diseases were classified according to the ICD-10 codes. Admissions data were accessed for records with a primary diagnosis of renal disease (N00 - N39). Primary diagnoses were obtained for both inpatient and ED admissions, and also up to two secondary diagnoses were obtained for inpatient admissions. Secondary diagnoses could not be obtained for ED admissions due to South Australian (SA) Department of Health protocol. Admissions were then further classified on specific primary and/or secondary diagnoses for eight renal 
Table 1 Descriptive statistics for temperature

\begin{tabular}{llllll}
\hline Temperature & Mean & SD & 5th percentile & 95th percentile & Median \\
\hline Maximum & 27.4 & 6.26 & 18.2 & 38.7 & 26.7 \\
Minimum & 15.54 & 4.48 & 8.8 & 23.7 & 15 \\
Average & 21.47 & 4.94 & 14.1 & 30.85 & 20.85
\end{tabular}

Descriptive statistics for daily dry bulb maximum, minimum and average temperature in Adelaide from 1 July 2003 to 31 March 2014 excluding the warm season (October - March)

diseases. These diseases were urolithiasis (N20 - N23), renal failure (N17 - N19.9), AKI (N17.0-17.9), CKD (N18.1 N18.9), UTIs (N10 - N12, N30, and N39.0-39.2), LUTIs (N30; N39.0 - N39.2), and pyelonephritis (N10 - N12). UTIs were investigated (i) collectively (pyelonephritis and LUTIs) to enable comparison with previous studies that did not subclassify UTI based on the site of infection $[3,41]$ and (ii) separately to provide more detailed information. Similarly, both AKI and CKD were investigated both separately and collectively, as renal failure, for comparison with previous studies that grouped AKI and CKD together [30].

\section{Data analyses}

Negative binomial (NB) regression models were used to estimate incidence rate ratios (IRRs) for daily admissions for various renal diseases (outcome variables) per $1^{\circ} \mathrm{C}$ increase in maximum, minimum and average temperature. Negative binomial models were deemed appropriate because of the overdispersion in the data. The models were adjusted for the effects of year, month, day of the week and holidays by including categorical variables for each covariate, and the outcomes were aggregated by day. Separate regression models were generated for inpatient and ED admissions. Models were time-stratified including only admissions occurring within the warm season (October to March), because the focus of the study was heat-related renal morbidity; including the cold season could introduce the confounding effect of cold on renal disease incidence [11, 12 , $42,43]$. Years were assigned from 1 July to 30 June (financial years) to ensure continuity across successive warm seasons. Secondary analyses were performed to (i) examine renal admissions following a lag period of 1-5 days after daily temperatures, (i) repeat the primary analysis with further stratification by gender, and (iii) repeated the primary analysis with stratification by age instead of gender ( $<65$ years and $\geq 65$ years old). All statistical analyses were conducted using Stata v13.0 (Statacorp, Texas, USA) with a significance level of $P<0.05$.

NB models were used because the outcome variables were counts, and these models are appropriate for overdispersed data. Goodness-of-fit tests were undertaken to indicate if Poisson models, the standard model of choice for count variables, fit the data [44]. These tests indicated a poor fit, as shown in Appendix 1. As the data contains very few zero values, the poor fit was likely secondary to overdispersion, justifying the use of NB models.

The primary statistical models can be represented by the equation:

$$
\begin{aligned}
\log _{\mathrm{e}}\left(\mathrm{N}_{\text {renal }}\right)= & \beta_{0}+\beta_{1} \text { temp }+\beta_{2} \text { holiday } \\
& +\sum_{0 \leq \mathrm{m} \leq 5}\left(\beta_{3+\mathrm{m}} \text { month }_{\mathrm{m}}\right) \\
& +\sum_{0 \leq \mathrm{n} \leq 6}\left(\beta_{9+\mathrm{n}} \text { day }_{\mathrm{n}}\right) \\
& +\sum_{0 \leq \mathrm{o} \leq 10}\left(\beta_{16+\mathrm{o}} \text { year }_{\mathrm{o}}\right)+\mathrm{u}
\end{aligned}
$$

$N$ designates the expected number of admissions for the specified renal disease renal. Temp is a variable representing daily temperature across all the days included in the study, specified as either maximum, minimum or average temperature. $\beta_{1}$ is the regression coefficient representing the effect of a $1^{\circ} \mathrm{C}$ increase in temp. $\operatorname{Exp}\left(\beta_{1}\right)$ is the calculated IRR for an increase in admissions per $1^{\circ} \mathrm{C}$ increase in temperature. In short, $\beta_{1}$ temp represents the effect of temperature. Similarly $\beta_{2}$ holiday represents the effect of whether the day was a public holiday. $\beta_{3+m}$ month $_{m}$ represents the effect of the month; using a categorical variable for each month $(m)$ from October to March. Similarly, $\beta_{9+n} d a y_{n}$ represents the effect of the day of the week, using a categorical variable for each day of the week (n). $\beta_{16+o}$ year $r_{o}$ represents the effect of the year, using a categorical variable for each financial year (o) within this study. $\beta_{O}$ and $u_{t}$ represent estimated constants in the model; $u_{t}$ is specifically included in NB models to account for extra variance.

\section{Results}

A total of 3927 days were included in the study period, with a total of 83,519 ED and 42,957 inpatient admissions for renal disease. Table 2 provides summary statistics for daily incidence of inpatient and ED admissions for specific renal diseases, showing positively skewed distributions for renal admissions. Mean daily admissions for renal diseases during the warm season were 11.5 for inpatient and 22.4 for ED admissions.

Figure 1 shows the incidence of mean daily admissions for all renal disease and urolithiasis plotted against year, month and day of the week. Admissions were highest during the warmest months (December - March) and from Monday to Friday. Mean daily admissions for renal failure, AKI, CKD, UTIs, LUTIs and pyelonephritis showed similar trends in relation to time (data not shown). Mean daily admissions for renal diseases were plotted against daily maximum temperature rounded to the nearest degree for ED and inpatient admissions (Fig. 2 and Fig. 3 respectively). The relationships between admissions and temperature appeared linear and positive as evidenced by the line of best fit. Stronger relationships with temperature were apparent for total 
Table 2 Summary statistics for admissions for renal disease

\begin{tabular}{|c|c|c|c|c|c|c|c|c|c|c|c|}
\hline \multirow{4}{*}{$\begin{array}{l}\text { Description } \\
\text { Total renal }\end{array}$} & \multirow{4}{*}{$\begin{array}{l}\text { Observational time period (days) } \\
\text { Total: } 3927\end{array}$} & \multicolumn{8}{|c|}{ Daily incidence of admissions } & \multicolumn{2}{|c|}{ Total admissions } \\
\hline & & \multicolumn{4}{|l|}{$\mathrm{ED}$} & \multicolumn{4}{|c|}{ Inpatient } & \multirow{3}{*}{$\begin{array}{l}\mathrm{ED} \\
83,519\end{array}$} & \multirow{3}{*}{$\begin{array}{l}\text { Inpatient } \\
42,957\end{array}$} \\
\hline & & \multirow{2}{*}{$\begin{array}{l}\text { Mean } \\
21.27\end{array}$} & \multirow{2}{*}{$\frac{S D}{6.04}$} & \multicolumn{2}{|c|}{ Min Max } & \multirow{2}{*}{$\begin{array}{l}\text { Mean } \\
10.94\end{array}$} & \multirow{2}{*}{$\frac{S D}{4.25}$} & \multicolumn{2}{|c|}{ Min Max } & & \\
\hline & & & & 5 & 46 & & & 1 & 32 & & \\
\hline \multirow[t]{2}{*}{ disease } & Cold season: 1922 & 20.26 & 5.53 & 5 & 42 & 10.32 & 3.90 & 1 & 28 & 38,931 & 19,834 \\
\hline & Warm season: 2005 & 22.24 & 6.35 & 8 & 46 & 11.53 & 4.48 & 1 & 32 & 44,588 & 23,123 \\
\hline \multirow[t]{3}{*}{ Urolithiasis } & Total: 3927 & 4.88 & 2.52 & 0 & 18 & 2.09 & 1.54 & 0 & 10 & 19,171 & 8206 \\
\hline & Cold season: 1922 & 4.38 & 2.23 & 0 & 15 & 1.86 & 1.44 & 0 & 9 & 8409 & 3578 \\
\hline & Warm season: 2005 & 5.37 & 2.69 & 0 & 18 & 2.31 & 1.60 & 0 & 10 & 10,762 & 4628 \\
\hline \multirow[t]{3}{*}{ Renal failure } & Total: 3927 & 1.79 & 1.53 & 0 & 13 & 1.84 & 1.53 & 0 & 13 & 7024 & 7213 \\
\hline & Cold season: 1922 & 1.70 & 1.46 & 0 & 7 & 1.75 & 1.47 & 0 & 8 & 3263 & 3359 \\
\hline & Warm season: 2005 & 1.88 & 1.58 & 0 & 13 & 1.92 & 1.58 & 0 & 13 & 3761 & 3854 \\
\hline \multirow[t]{3}{*}{ AKI } & Total: 3927 & 1.08 & 1.19 & 0 & 10 & 1.40 & 1.34 & 0 & 12 & 4253 & 5483 \\
\hline & Cold season: 1922 & 0.99 & 1.08 & 0 & 6 & 1.29 & 1.24 & 0 & 7 & 1904 & 2481 \\
\hline & Warm season: 2005 & 1.17 & 1.27 & 0 & 10 & 1.50 & 1.42 & 0 & 12 & 2349 & 3002 \\
\hline \multirow[t]{3}{*}{ CKD } & Total: 3927 & 0.50 & 0.73 & 0 & 5 & 0.86 & 0.99 & 0 & 6 & 1959 & 3390 \\
\hline & Cold season: 1922 & 0.51 & 0.75 & 0 & 5 & 0.85 & 0.99 & 0 & 5 & 976 & 1634 \\
\hline & Warm season: 2005 & 0.49 & 0.70 & 0 & 4 & 0.88 & 0.98 & 0 & 6 & 983 & 1756 \\
\hline \multirow[t]{3}{*}{ UTI } & Total: 3927 & 13.70 & 4.39 & 2 & 33 & 6.36 & 2.92 & 0 & 19 & 53,789 & 24,985 \\
\hline & Cold season: 1922 & 13.30 & 4.19 & 2 & 31 & 6.12 & 2.75 & 0 & 19 & 25,559 & 11,754 \\
\hline & Warm season: 2005 & 14.08 & 4.55 & 2 & 33 & 6.60 & 3.05 & 0 & 19 & 28,230 & 13,231 \\
\hline \multirow[t]{3}{*}{ Lower UTI } & Total: 3927 & 12.27 & 3.97 & 1 & 31 & 5.35 & 2.64 & 0 & 15 & 48,203 & 20,997 \\
\hline & Cold season: 1922 & 11.97 & 3.80 & 1 & 26 & 5.19 & 2.49 & 0 & 14 & 23,004 & 9978 \\
\hline & Warm season: 2005 & 12.57 & 4.11 & 2 & 31 & 5.50 & 2.76 & 0 & 15 & 25,199 & 11,019 \\
\hline \multirow[t]{3}{*}{ Pyelonephritis } & Total: 3927 & 1.42 & 1.34 & 0 & 9 & 1.21 & 1.13 & 0 & 7 & 5586 & 4755 \\
\hline & Cold season: 1922 & 1.33 & 1.29 & 0 & 9 & 1.10 & 1.07 & 0 & 6 & 2555 & 2123 \\
\hline & Warm season: 2005 & 1.51 & 1.38 & 0 & 9 & 1.31 & 1.17 & 0 & 7 & 3031 & 2632 \\
\hline
\end{tabular}

Summary statistics for daily admission rates and total admissions for renal diseases in Adelaide from 1 July 2003 to 31 March 2014 . Admissions are divided into cold season (April - September) and warm season (October - March). Both emergency department (ED) and inpatient admissions are included. Accompanying the mean daily admission rate (mean) are the standard deviation (SD) and the minimum (min) and maximum (max) number of daily admissions

renal disease (a), urolithiasis (b), renal failure (c) and AKI (d), with weaker relationships apparent for the other renal categories. The results between ED and inpatient admissions were similar apart from a greater percentage of increase in UTI and LUTI inpatient admissions compared to ED admissions. At very high temperatures (starting at approximately $40^{\circ} \mathrm{C}$ ), there were fewer observations for daily admission counts; this showed as greater scattering and the presence of outliers. These outliers are likely to have had minimal impact on estimating the effect of temperature because they only represented a very small number of days.

Table 3 shows estimated IRRs for each renal disease outcome in relation to a $1^{\circ} \mathrm{C}$ increase in daily maximum, minimum and average temperature for inpatient and $\mathrm{ED}$ admissions. A positive relationship was identified for total renal disease, urolithiasis, renal failure and AKI for both inpatient and ED admissions, as well as for UTI and LUTI for inpatient admissions. Minimum temperature (but not maximum and average temperature) was also associated with statistically significant increase for ED admissions for CKD, UTI and LUTI. Minimum temperature appeared to be associated with the greatest increase followed by average temperature. The highest effect was apparent for admissions for AKI. There was a 3.7\% increase in ED admissions for AKI for each $1^{\circ} \mathrm{C}$ increase in minimum temperature (IRR $=1.037$, 95\% CI 1.026-1.048 $P<0.001$ ). A comparable effect was also observed for renal failure for both ED and inpatient admissions in association with $1^{\circ} \mathrm{C}$ increases in average and minimum temperature, with the other outcomes either showing a smaller increase or no significant effect. Pyelonephritis admissions showed no association with any of the temperature metrics. These results are also shown graphically in Fig. 4.

Incidence for daily admissions for renal disease in relation to a $1^{\circ} \mathrm{C}$ increase in daily temperature (maximum, minimum and average) for admissions for all the renal categories following a lag period of $1-5$ days were examined. The results show 

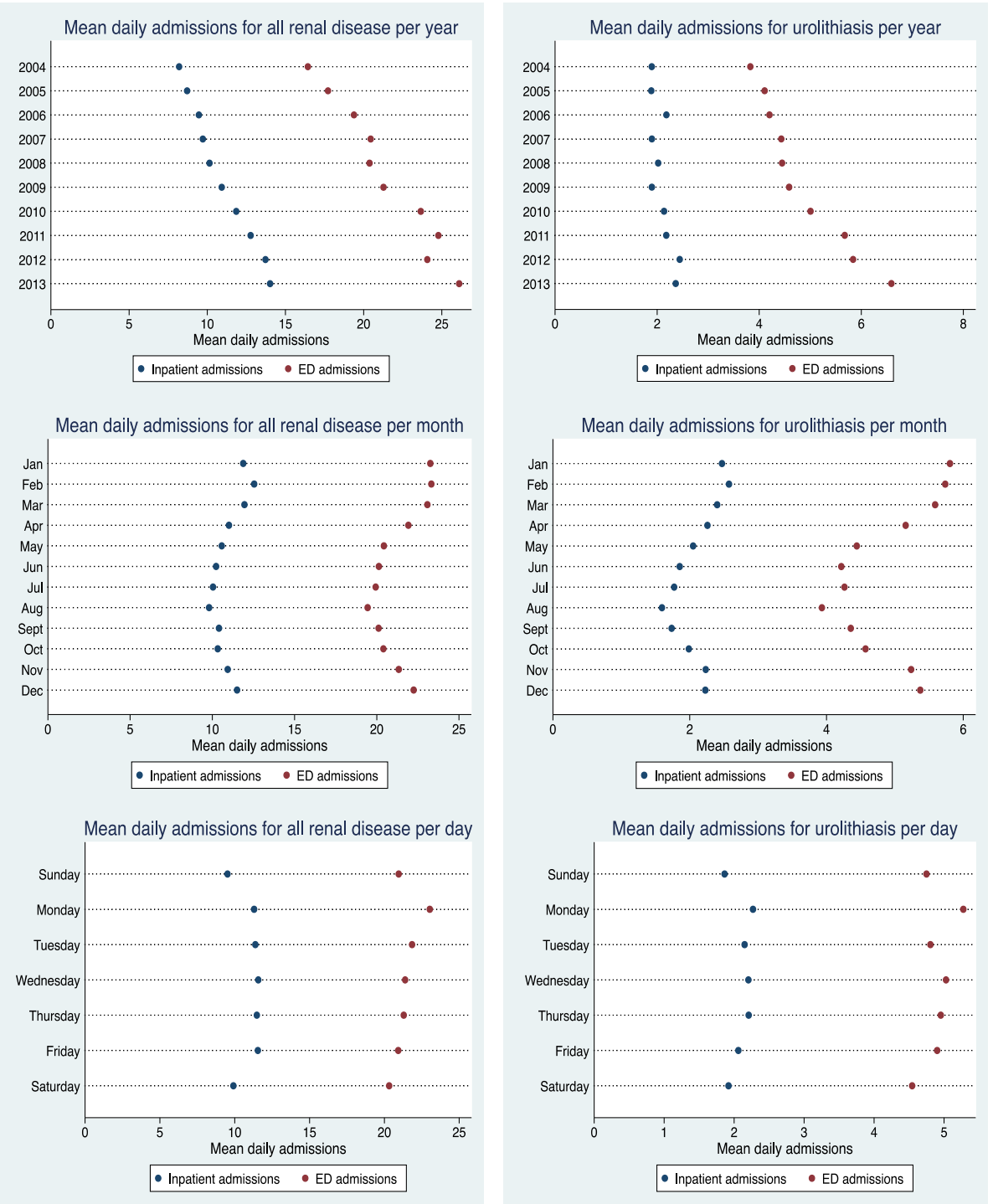

Fig. 1 Mean daily renal admissions by year, month and day. Mean daily admissions for total renal disease and urolithiasis plotted against year, month and day of the week in Adelaide. Both inpatient and emergency department (ED) admissions were included. Holidays were excluded from the data. The time period illustrated in the dot graphs examining month and day of the week was 1 July 2003-31 March 2014

a lag effect of temperature was associated with all the renal categories and daily temperature (maximum, minimum and average) with the exception of pyelonephritis. This lag effect appeared to last the longest for total renal disease, urolithiasis, renal failure and AKI. Admissions for CKD were associated with a lag effect even if admission were not increased on the day when the daily temperatures were recorded. Similar to the admissions rates without a lag period, IRRs were generally highest when associated with minimum daily temperature followed by average temperature and then maximum temperature. The effect of minimum temperature appeared to be strongest on the day as opposed to following a lag period, with the exception of a very small increase in IRR for CKD for both IP and ED admissions (0.1\%). When examining maximum temperature, however, the effect appeared to be strongest 1-3 days after the temperature exposure. The lag period analyses, and accompanying graphs for maximum and minimum temperature, are shown in Appendix 2.

The effects of gender on the associations between renal admissions and temperature were examined; however, there were less statistically relevant results when looking at genders separately, likely due to reduced power. For male ED presentations, results were statistically significant for total renal disease and urolithiasis. For male inpatient presentations, results were statistically significant for AKI and CKD instead. For ED presentations among females, results were statistically significant for renal failure, AKI, UTIs and LUTIs. The only statistically significant changes in female inpatient presentations 

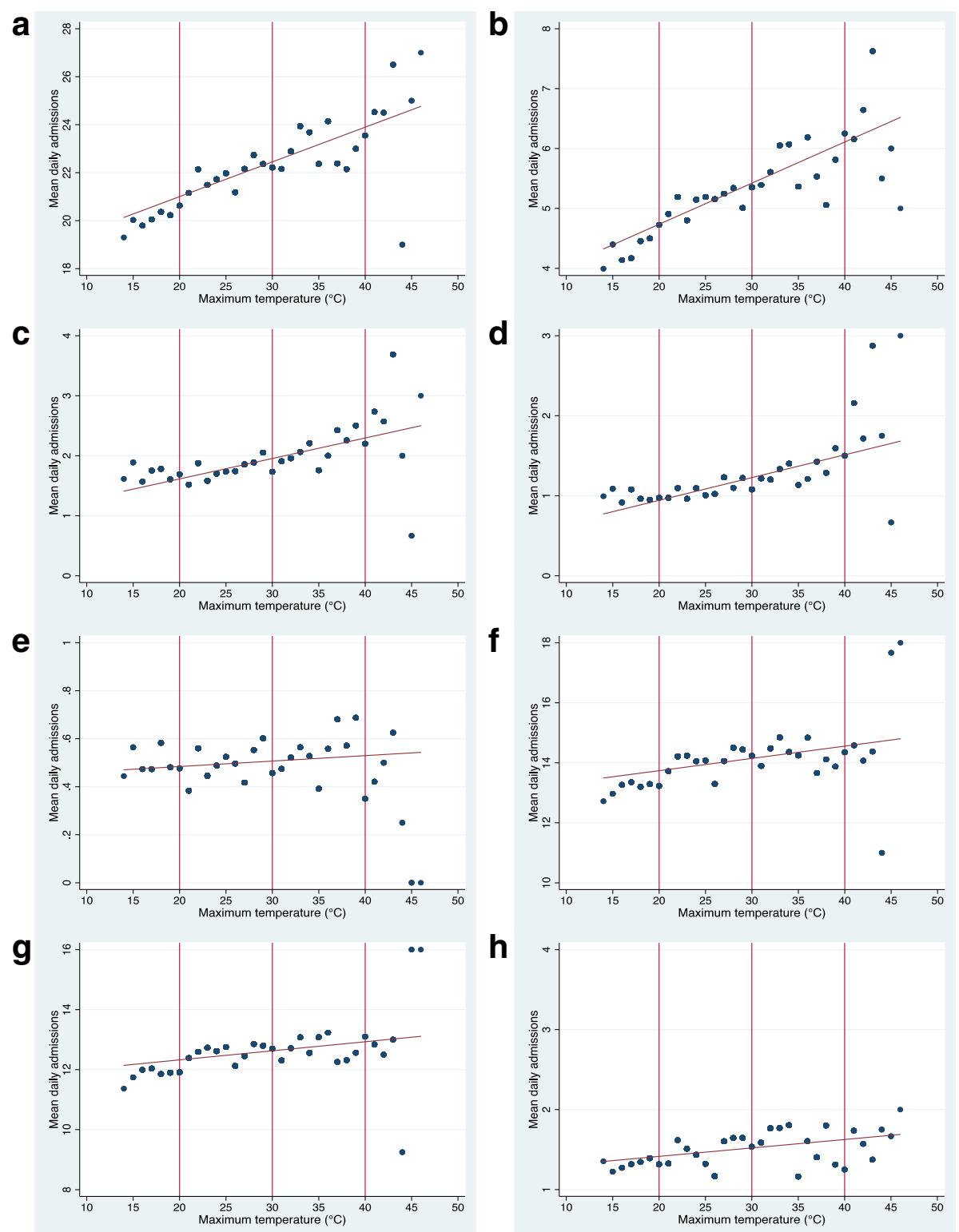

Fig. 2 Daily maximum temperature and mean hospital emergency department renal admissions. Descriptive graphs for mean number of daily hospital emergency department admissions for renal disease in relation to daily maximum temperature, during the warm season (October - March) in Adelaide from 1 July 2003 to 31 March 2014. Data points are separated by 1. Graphs are in relation to (a) total renal disease; (b) urolithiasis; (c) renal failure; (d) AKl; (e) CKD; (f) UTI; (g); lower UTT; (h) pyelonephritis

were with admissions for urolithiasis. Both genders had increased ED admissions for total renal disease. Males also showed increased ED admissions for urolithiasis and renal failure, whilst females demonstrated increased ED admissions for renal failure, AKI, UTIs and LUTIs. The gender-stratified analyses, including graphs, are available in Appendix 3.

The effects of age group ( $<65$ years and $\geq 65$ years) on the associations between renal admissions and temperature were examined. In those aged $<65$ years old, there were statistically significant increases in ED admissions for total renal disease, urolithiasis, renal failure, and AKI associated with daily temperature (maximum, minimum and average). For elderly-related admissions, the only statistically significant increase in inpatient admissions was for pyelonephritis. The age-stratified analyses, including graphs, are available in Appendix 4.

\section{Discussion}

This study investigated the associations between temperature and admissions for a range of specific renal diseases in Adelaide, a city with a temperate climate. No previous Australian study has investigated the link between heat 
a

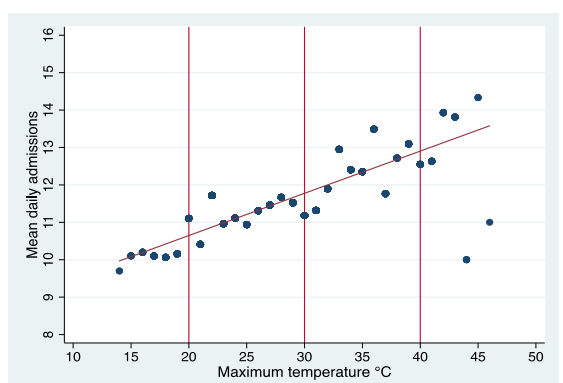

C

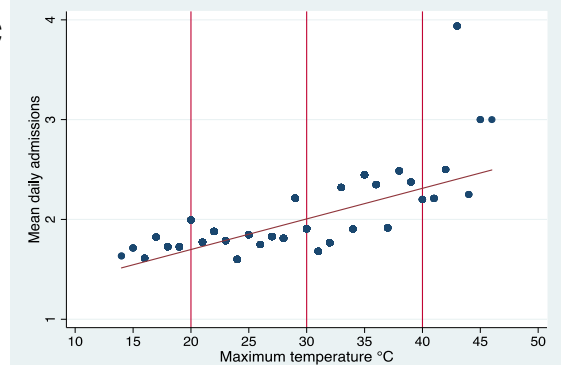

e

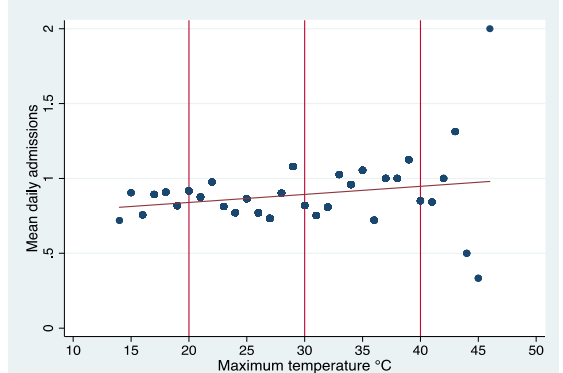

g

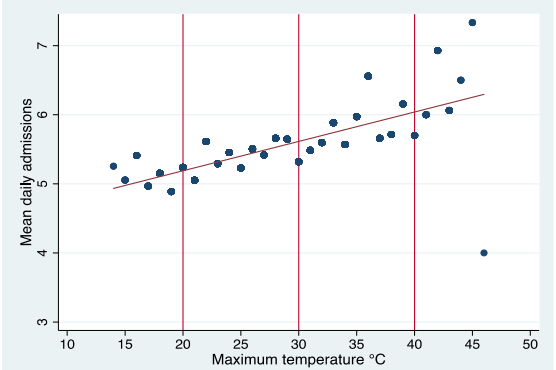

b
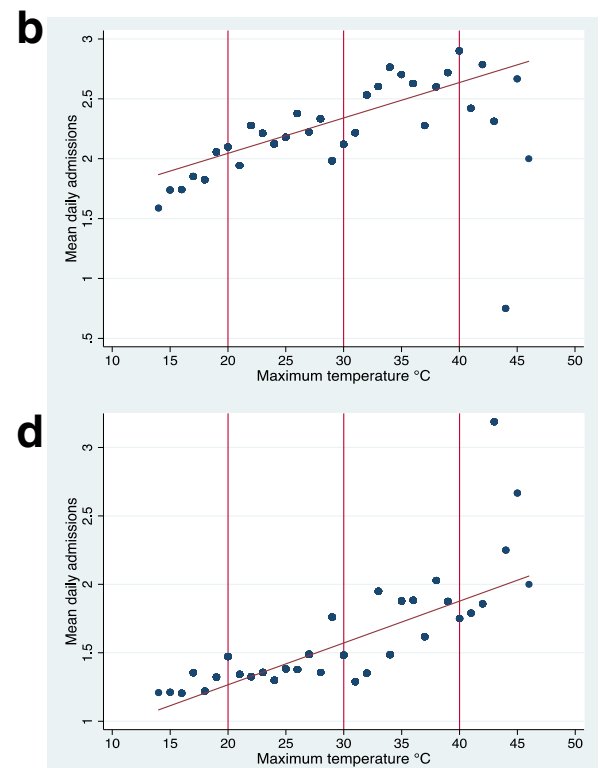

f

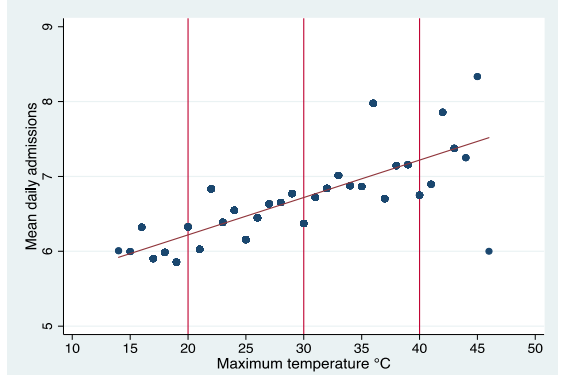

h

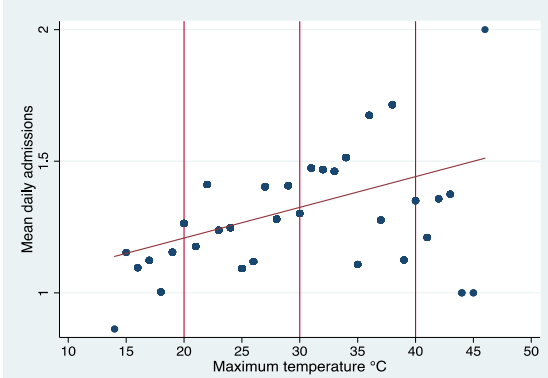

Fig. 3 Daily maximum temperature and mean hospital inpatient renal admissions. Descriptive graphs for mean number of daily hospital inpatient admissions for renal disease in relation to daily maximum temperature rounded to the nearest $1{ }^{\circ} \mathrm{C}$ during the warm season (October - March) in Adelaide from 1 July 2003 to 31 March 2014. Data points are separated by $1^{\circ}$. Graphs are in relation to (a); total renal disease (b); urolithiasis (c); renal failure (d); AKI (e); CKD (f); UTI (g); lower UTI (h); pyelonephritis

exposure and urolithiasis, UTIs and CKD at a population level. Furthermore it is the only SA study that examines the effect of lag periods and gender on heat exposure with regards to renal disease. The only previous SA study in Adelaide that investigated a direct link between temperature and renal disease, only assessed the relationship above predefined temperature thresholds, and it did not investigate specific renal categories [12].

This study showed an increased incidence of renal disease, urolithiasis, renal failure (both acute and chronic) and UTIs, specifically lower UTIs, in relation to daily temperature (maximum, minimum and average). Inpatient and ED admissions for total renal disease, renal failure and AKI increased with daily maximum, minimum and average temperatures, and ED admissions for CKD increased with minimum temperature. The results for total renal disease and AKI are consistent with previous studies in Adelaide and Sydney [4, $10,12,43]$. An increase was also found in inpatient admissions for UTIs and LUTIs in association with increasing temperature. Older patients are normally more prone to UTIs, and concurrent dehydration stress could predispose them further [41]. We did not find a significant increase in 
Table 3 Regression analysis for temperature

\begin{tabular}{|c|c|c|c|c|c|c|c|}
\hline \multirow{2}{*}{$\frac{\text { Temperature data }}{\text { Maximum }}$} & \multirow{2}{*}{$\begin{array}{l}\text { Admission data } \\
\text { ED }\end{array}$} & \multirow{2}{*}{$\begin{array}{l}\text { Disease } \\
\text { All renal disease }\end{array}$} & \multirow{2}{*}{$\frac{\operatorname{IRR}}{1.004}$} & \multicolumn{3}{|l|}{$95 \% \mathrm{Cl}$} & \multirow{2}{*}{$\frac{P \text {-value }}{<0.001}$} \\
\hline & & & & 1.002 & - & 1.005 & \\
\hline & & Urolithiasis & 1.006 & 1.003 & - & 1.010 & $<0.001$ \\
\hline & & Renal failure & 1.018 & 1.012 & - & 1.024 & $<0.001$ \\
\hline & & AKI & 1.023 & 1.016 & - & 1.031 & $<0.001$ \\
\hline & & CKD & 1.005 & 0.994 & - & 1.016 & 0.365 \\
\hline & & UTI & 1.001 & 0.999 & - & 1.003 & 0.411 \\
\hline & & Lower UTI & 1.001 & 0.999 & - & 1.003 & 0.507 \\
\hline & & Pyelonephritis & 1.002 & 0.995 & - & 1.009 & 0.547 \\
\hline & Inpatient & All renal disease & 1.006 & 1.004 & - & 1.009 & $<0.001$ \\
\hline & & Urolithiasis & 1.007 & 1.002 & - & 1.012 & 0.009 \\
\hline & & Renal failure & 1.016 & 1.010 & - & 1.022 & $<0.001$ \\
\hline & & AKI & 1.020 & 1.013 & - & 1.026 & $<0.001$ \\
\hline & & CKD & 1.006 & 0.997 & - & 1.014 & 0.171 \\
\hline & & UTI & 1.004 & 1.001 & - & 1.008 & 0.005 \\
\hline & & Lower UTI & 1.005 & 1.002 & - & 1.009 & 0.002 \\
\hline & & Pyelonephritis & 1.002 & 0.996 & - & 1.009 & 0.472 \\
\hline \multirow[t]{16}{*}{ Minimum } & ED & All renal disease & 1.009 & 1.006 & - & 1.011 & $<0.001$ \\
\hline & & Urolithiasis & 1.015 & 1.010 & - & 1.020 & $<0.001$ \\
\hline & & Renal failure & 1.030 & 1.022 & - & 1.039 & $<0.001$ \\
\hline & & AKI & 1.037 & 1.026 & - & 1.048 & $<0.001$ \\
\hline & & CKD & 1.017 & 1.001 & - & 1.033 & 0.036 \\
\hline & & UTI & 1.004 & 1.000 & - & 1.007 & 0.023 \\
\hline & & Lower UTI & 1.003 & 1.000 & - & 1.006 & 0.045 \\
\hline & & Pyelonephritis & 1.006 & 0.996 & - & 1.015 & 0.245 \\
\hline & Inpatient & All renal disease & 1.012 & 1.008 & - & 1.015 & $<0.001$ \\
\hline & & Urolithiasis & 1.014 & 1.007 & - & 1.022 & $<0.001$ \\
\hline & & Renal failure & 1.024 & 1.015 & - & 1.032 & $<0.001$ \\
\hline & & AKI & 1.028 & 1.019 & - & 1.038 & $<0.001$ \\
\hline & & CKD & 1.011 & 0.999 & - & 1.023 & 0.068 \\
\hline & & UTI & 1.008 & 1.003 & - & 1.012 & $<0.001$ \\
\hline & & Lower UTI & 1.009 & 1.004 & - & 1.014 & $<0.001$ \\
\hline & & Pyelonephritis & 1.005 & 0.995 & - & 1.014 & 0.346 \\
\hline \multirow[t]{13}{*}{ Average } & $\mathrm{ED}$ & All renal disease & 1.007 & 1.004 & - & 1.009 & $<0.001$ \\
\hline & & Urolithiasis & 1.012 & 1.007 & - & 1.016 & $<0.001$ \\
\hline & & Renal failure & 1.028 & 1.020 & - & 1.036 & $<0.001$ \\
\hline & & AKI & 1.035 & 1.025 & - & 1.045 & $<0.001$ \\
\hline & & CKD & 1.011 & 0.997 & - & 1.026 & 0.125 \\
\hline & & UTI & 1.002 & 0.999 & - & 1.005 & 0.121 \\
\hline & & Lower UTI & 1.002 & 0.999 & - & 1.005 & 0.184 \\
\hline & & Pyelonephritis & 1.004 & 0.995 & - & 1.013 & 0.364 \\
\hline & Inpatient & All renal disease & 1.010 & 1.007 & - & 1.013 & $<0.001$ \\
\hline & & Urolithiasis & 1.012 & 1.005 & - & 1.019 & 0.001 \\
\hline & & Renal failure & 1.023 & 1.016 & - & 1.031 & $<0.001$ \\
\hline & & AKI & 1.029 & 1.020 & - & 1.037 & $<0.001$ \\
\hline & & CKD & 1.010 & 0.999 & - & 1.021 & 0.087 \\
\hline
\end{tabular}


Table 3 Regression analysis for temperature (Continued)

\begin{tabular}{|c|c|c|c|c|c|c|c|}
\hline Temperature data & Admission data & Disease & IRR & $95 \% \mathrm{Cl}$ & & & $P$-value \\
\hline & & UTI & 1.007 & 1.003 & - & 1.011 & 0.001 \\
\hline & & Lower UTI & 1.008 & 1.004 & - & 1.013 & $<0.001$ \\
\hline & & Pyelonephritis & 1.004 & 0.995 & - & 1.013 & 0.378 \\
\hline
\end{tabular}

Estimated incidence rate ratios (IRRs) and associated 95\% confidence intervals and $P$-values for daily admissions for renal diseases in relation to an increase in daily temperature (maximum, minimum and average) per $1^{\circ} \mathrm{C}$ during the warm seasons (October - March) in Adelaide from 1 July 2003 to 31 March 2014. Both emergency department (ED) and inpatient admissions were included

UTIs in the population aged over 65 years, however this may have been due to a decrease in statistical power because of sample size. ED and inpatient admission rates for urolithiasis increased with higher temperatures. Australian studies have demonstrated seasonal variation in the incidence of renal colic - highest in summer and autumn [27, 28, 45], which is consistent with our findings. Admissions for AKI showed the greatest increase in relation to heat exposure with maximum, minimum and average daily temperature. Dehydration has a stronger established link with AKI [46]. Comparable effects of temperature on renal failure (AKI and CKD collectively) were observed, which were likely due to the increased AKI admissions. On a similar note, as the large majority of total renal disease cases were AKI and urolithiasis, these admissions are likely to explain the increased admissions for total renal disease with heat exposure.

High temperatures are believed to predispose to renal disease due to heat-induced sweating, leading to decreased extracellular fluid (ECF) and subsequent dehydration [14]. In the case of urolithiasis, low ECF leads to increased secretion of vasopressin. Vasopressin promotes reabsorption of water from renal filtrate causing increased urinary concentration. This increases the concentration of calcium and uric acid, predisposing to supersaturation of these solutes and hence accelerating the rate of stone formation [14, 25, 41, 47]. Stones can grow over hours in an appropriate urinary environment [48]. Low ECF, with subsequent decreased blood volume, results in less blood being filtrated by the kidney and hence a decreased glomerular filtration rate. This can lead to AKI $[46,49]$. Studies have shown dehydration is linked to a higher risk of both AKI and CKD [45, 50]. Whilst there is evidence to suggest a positive association exists between dehydration and CKD, including an Australian study, a precise mechanism has not been established $[41,45,50,51]$. A proposed mechanism is that prolonged elevated vasopressin secretion, induced by chronic dehydration, contributes to progressive tubulointerstitial damage, predisposing to CKD $[41,52]$. A USA study showed increased admissions for UTIs during heatwaves [3]. Chronic low urine output, which can result from decreased urine volume secondary to dehydration, has been linked to a higher risk of UTI [41]. Hypothesized, but unproven, mechanisms for this observation stem from decreased water within the urine. This leads to increased bacterial concentration (predisposing to infection) and increased urine osmolality with subsequent urine acidity that promotes bacterial adhesion to the urinary epithelium [41]. Decreased urinary volume can also result in less "flushing out" of bacteria [41]. These mechanisms for dehydration resulting in renal disease are outlined in Fig. 5.

CKD was the only renal category in this study that required a lag period in order to indicate a statistically significant increase in admissions. This may reflect the chronic nature of CKD in which the clinical effect of worsening renal function secondary to dehydration does not present immediately but rather predisposes to an admission approximately $1-3$ days later.

The effect of increasing temperature on ED admissions for urolithiasis was higher in males than females. This is consistent with the observation that men are more likely to develop calcium and uric stones and that stones can develop quickly following acute heat exposure $[14,47,53]$. This increased risk is amplified with increasing temperature. [14]. In contrast, the effect of increasing temperature on ED admissions for UTIs and LUTIs was only apparent in females. This was probably because females are at greater risk of developing UTIs; one study showed they are 50 times more frequent in adult women without accounting for heat exposure [41].

It is known that infants, children, and particularly the elderly, are more susceptible to heat-related morbidity than other age groups $[4,11,17,42,54-56]$. When examining the effect of age in this study, those aged $<65$ had statistically significant results for ED admissions for urolithiasis, renal failure and AKI, but not the elderly. This could have reflected the acute nature of dehydration-predisposing activities that those aged $<65$ undertake, such as intense exercise or severe occupational heat exposure, whereas the onset of dehydration in the elderly may be more gradual. Alternatively the difference between the results in the two age groups could have resulted from a lack of statistical power. It should be noted that there were less statistically relevant results when stratifying by genders and age. For example, inpatient admissions for UTIs and LUTIs were statistically significant for maximum, minimum and average temperature for both genders combined, but no significance was found when examining the genders individually.

Adverse health effects of extreme heat exposure are largely preventable [57]. The SA Government is undertaking prevention strategies to reduce morbidity during heat events. These strategies include media announcements raising awareness of heat events and advice to minimize heat- 


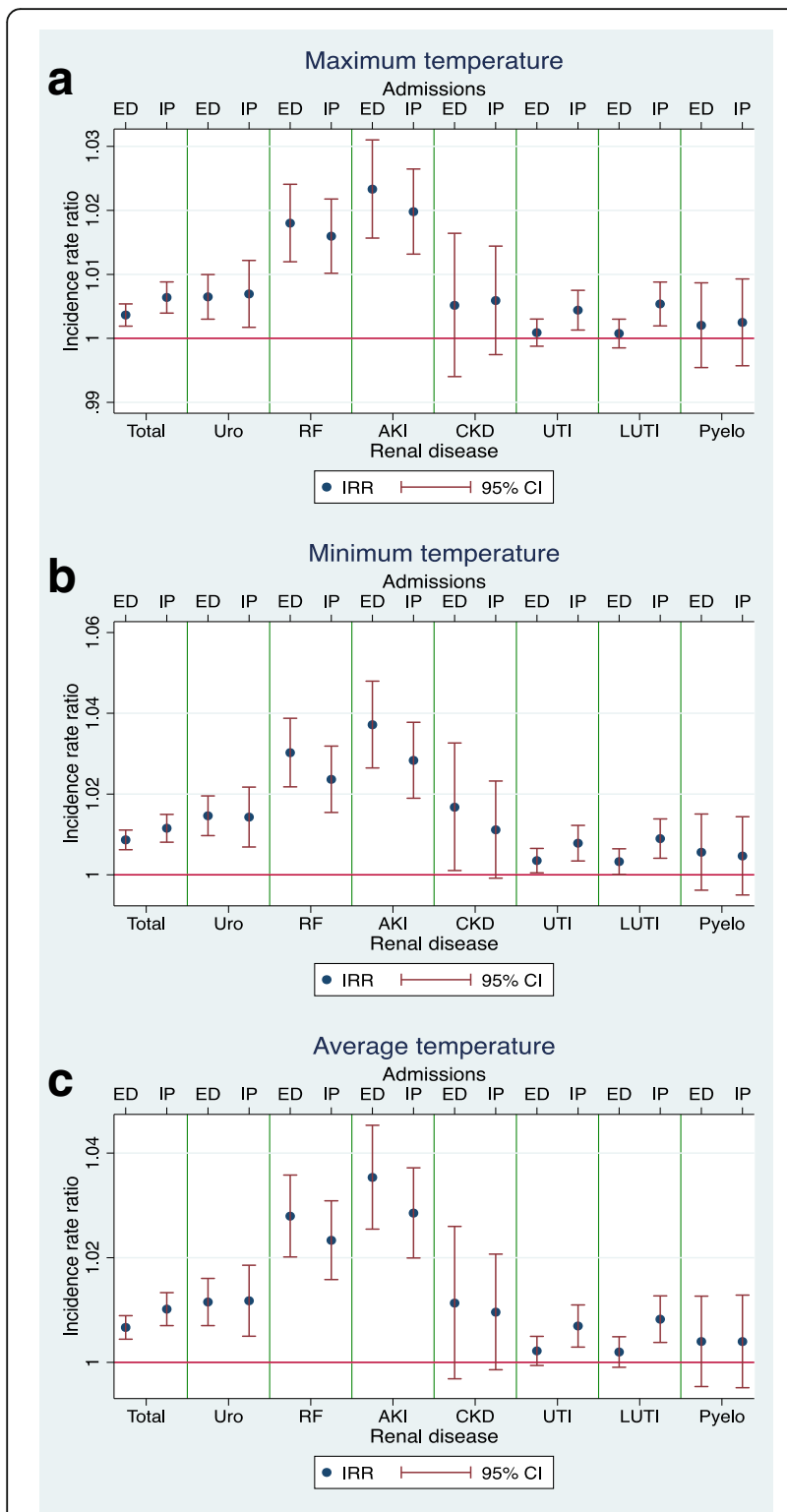

Fig. 4 Estimated incidence rate ratios (IRRs) for renal outcomes and daily temperature. Graphs for incidence rate ratios (IRRs) for daily admissions for renal diseases and associated 95\% confidence intervals $(95 \% \mathrm{Cl})$ in relation to daily temperature per $1{ }^{\circ} \mathrm{C}$, during the warm season (October - March) in Adelaide from 1 July 2003 to 31 March 2014. Both emergency department (ED) and inpatient (IP) admissions are included. Graphs are in relation to (a); maximum temperature (b); minimum temperature (c); average temperature. The renal categories represented are total renal disease (Total), urolithiasis (Uro), renal failure (RF), acute kidney injury (AKI), chronic kidney disease (CKD), urinary tract infections (UTI), lower urinary tract infections (LUTI) and pyelonephritis (Pyelo)

related morbidity [58]. Such advice includes maintaining adequate hydration, use of air conditioning, keeping out of the sun and cool clothing [58]. The increased risk of renal disease should also be advertised to the general public as part of these strategies. Certain individuals deemed to be more vulnerable to heat-related morbidity, including the elderly and some mental health clients, are targeted $[4,11$, 17, 42, 54-56, 58]. The assessment and monitoring of vulnerable individuals is carried out by community health managers [58]. These vulnerable individuals are further targeted by these strategies, such as phone calls to these individuals or their carers for additional heat event awareness and advice [58]. People with a significantly high risk of developing renal disease, as identified by clinicians, should also be included in this vulnerable group of individuals, because renal disease is more likely to occur during heatwaves. For example, in the case of AKI, fluid-restricted individuals or those taking nephrotoxic medications [46], and in the case of urolithiasis, patients with a past history of urolithiasis [28]. This is especially important for AKI, as it is associated with increased mortality [59]. Primary care and renal physicians should inform vulnerable patients of the risks and recommend preventative measures during their consultations, particularly shortly before and throughout the warm season. Furthermore health service providers could tailor these risk-reducing strategies to each individual patient, for example, by recommending a patient to rehydrate at set times during the day with a set volume at each time, and to have extra hydration following prolonged heat exposure such as during work. At a policy level, government and service providers should consider increasing the capacity for renal health care, particularly during the warm season, in preparation for the increase in renal disease frequency.

This study provides the most comprehensive examination of different renal disease categories in relation to heat exposure to date in Australia. Over 80,000 ED admissions and 40,000 inpatient admissions were tested in this study; the large sample size is necessary to provide adequate statistical power when examining subdivided renal categories. Multiple measures of temperature were tested to add reliability to the results and lag periods of up to five days following temperature exposure were assessed. This study also considered differences between genders and age groups.

This study has some limitations, including potential misclassification of heat exposure. Those without access to air conditioning have increased heat exposure, as air conditioners are protective for heat adverse outcomes [1, 60-63]. However, Adelaide has high air-conditioning coverage, therefore its impact should be minimum. This study did not account for humidity and air pollution, in particular ozone and particulate matter, which have been linked to greater heat-related morbidity; but this effect is minimal, and air pollution may not affect renal disease [12, 17, 18, $45,64,65]$. All temperature data were acquired from a single meteorological station, and, while this is representative of metropolitan Adelaide, it would have been more accurate to utilize data from multiple climate stations matched to the patients' home addresses. However, other stations 


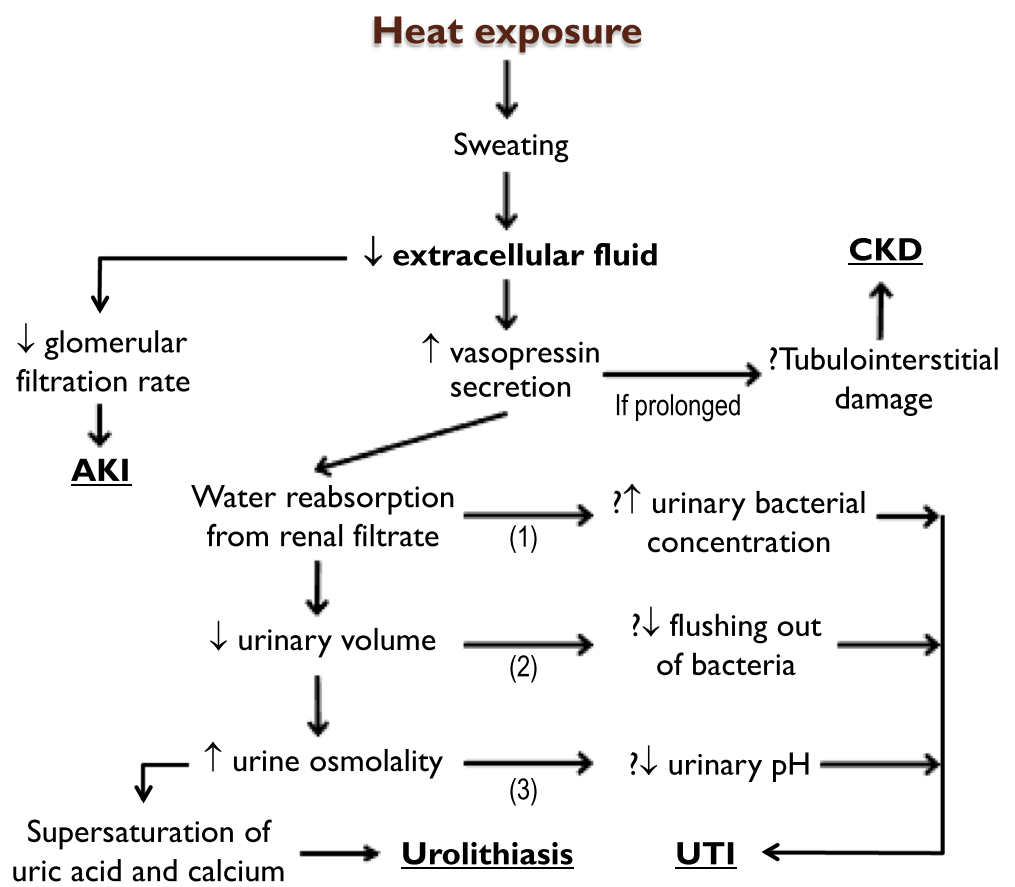

Fig. 5 Proposed mechanisms for heat exposure leading to renal disease. Heat exposure can induce sweating, leading to decreased extracellular fluid (ECF) with subsequent dehydration. This can lead to renal disease by a variety of mechanisms $[14,41,49]$

reporting meteorological data from metropolitan Adelaide, including Adelaide and Parafield Airports, showed similar temperatures to those of Kent Town [37]. When examining age, it would have been preferred to assess a number of age groups, such as children. However, the main concerning age, 65 and above (the elderly), was examined [4, 11, 17, 42, $55,56]$. With ICD-codes, diagnoses can be under-reported or miscoded $[3,11,26]$. Only up to two secondary diagnoses for inpatient admissions, and none for ED admissions, were included, hence the number of admissions were likely under-reported. Finally, medical complications attributed to heat events may occur at some time even without heat exposure; that is, the exposure would lead to an earlier complication instead of an additional one [3, 66, 67].

Further research is warranted to analyze individual renal diseases in more detail. To complement population based studies, a clinical audit trial could enable data to be collected from hospital records for targeted renal outcomes during heat events, revealing more comprehensive information regarding clinical, social and behavioral risk factors. These factors could include co-morbidities such as diabetes and heart failure that have been associated with worse outcomes during severe heat exposure [54, 68, 69]. Certain occupations, such as mining and agriculture, are risk factors due to occupational heat exposure, which is additive to seasonal exposure [5, 70-73]. Psychiatric conditions, impaired mobility, a greater number of co-morbidities, social isolation and low socio-economic status have been linked to adverse heat outcomes $[16,18,19,30,62,73,74]$.
Medications that can increase susceptibility to heatrelated renal disease by impairing thermotolerance, in particular psychotropic drugs, diuretics and $\beta$ blockers, should also be evaluated [11, 75-77]. The SA Extreme Heat Arrangements Plan, a SA government initiative which implements heat warning and targeted interventions during periods of extreme heat, has been shown to lower the rates of morbidity outcomes associated of renal disease [78]. This plan could be further evaluated by investigating its effectiveness on specific renal diseases.

\section{Conclusions}

An increased risk of specific renal categories was observed with increasing temperatures. This was most evident with AKI but was also observed with urolithiasis and UTIs, the latter especially with females. The results have implications for ongoing public health interventions aimed at preventing heat-related morbidity, by targeting individuals at greater risk of developing renal disease, including specific renal diseases, and improving community awareness of the risks with regards to heat and renal disease in Adelaide.

\section{Additional file}

Additional file 1: Daily temperature data (maximum and minimum) from the Bureau of Meteorlogy from a monitoring station in Kent Town (station 023090), Adelaide. The data extends from July 2003 to March 2014. (XLS 556 kb) 


\section{Appendix 1}
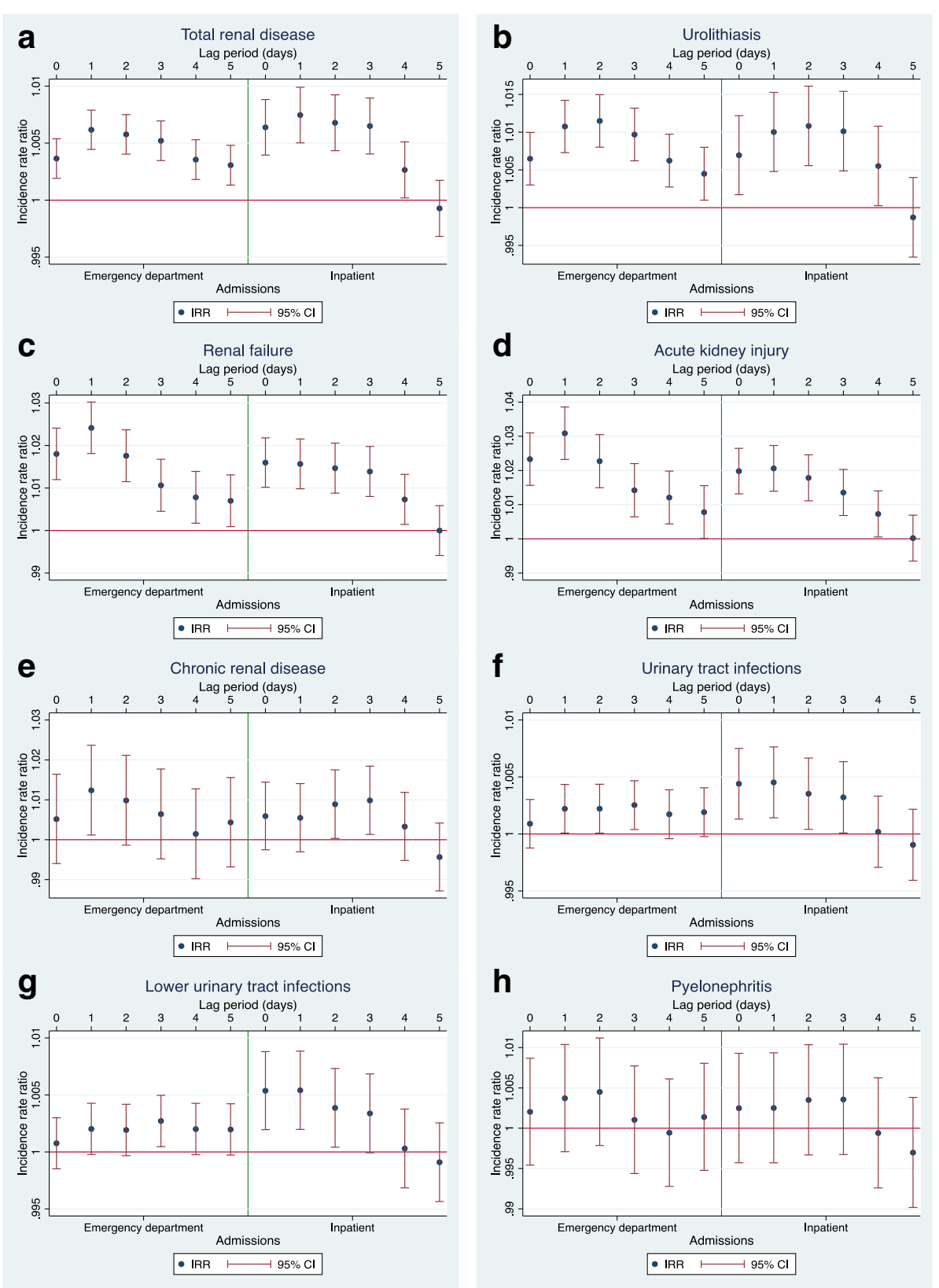

Fig. 6 Incidence rate ratios (IRRs) for renal outcomes and daily maximum temperature for lag periods of 0-5 days. Graphs for incidence rate ratios (IRRs) for daily admissions for renal diseases and associated $95 \%$ confidence intervals $(95 \% \mathrm{Cl}$ ) in relation to daily maximum temperature per $1{ }^{\circ} \mathrm{C}$, during the warm season (October - March) in Adelaide from 1 July 2003 to 31 March 2014. Admissions are listed for each day over a lag period of 0 to 5 days. The left sides of the graphs represent emergency department admissions, and the right sides represent inpatient

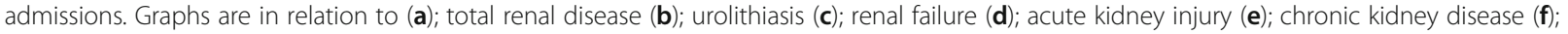
urinary tract infections $(\mathbf{g})$; lower urinary tract infections $(\mathbf{h})$; pyelonephritis 
Table 4 Poisson goodness-of-fit tests

\begin{tabular}{|c|c|c|c|}
\hline \multirow[t]{2}{*}{ Disease } & \multirow[t]{2}{*}{ Statistical test } & \multicolumn{2}{|c|}{ Daily maximum temperature (1980 df) } \\
\hline & & $E D$ & Inpatient \\
\hline \multirow[t]{4}{*}{ Total renal disease } & Deviance goodness-of-fit statistic & 2216.946 & 2271.521 \\
\hline & $P$-value & $<0.001$ & $<0.001$ \\
\hline & Pearson goodness-of-fit statistic & 2199.826 & 2244.133 \\
\hline & $P$-value & $<0.001$ & $<0.001$ \\
\hline \multirow[t]{4}{*}{ Urolithiasis } & Deviance goodness-of-fit statistic & 2290.703 & 2325.260 \\
\hline & $P$-value & $<0.001$ & $<0.001$ \\
\hline & Pearson goodness-of-fit statistic & 2150.742 & 2071.219 \\
\hline & $P$-value & 0.004 & 0.075 \\
\hline \multirow[t]{4}{*}{ Renal failure } & Deviance goodness-of-fit statistic & 2470.910 & 2387.224 \\
\hline & $P$-value & $<0.001$ & $<0.001$ \\
\hline & Pearson goodness-of-fit statistic & 2241.799 & 2133.986 \\
\hline & $P$-value & $<0.001$ & 0.008 \\
\hline \multirow[t]{4}{*}{ AKI } & Deviance goodness-of-fit statistic & 2438.874 & 2407.545 \\
\hline & $P$-value & $<0.001$ & $<0.001$ \\
\hline & Pearson goodness-of-fit statistic & 2294.101 & 2171.447 \\
\hline & $P$-value & $<0.001$ & 0.002 \\
\hline \multirow[t]{4}{*}{ CKD } & Deviance goodness-of-fit statistic & 1934.498 & 2279.640 \\
\hline & $P$-value & 0.764 & $<0.001$ \\
\hline & Pearson goodness-of-fit statistic & 1906.882 & 2069.318 \\
\hline & $P$-value & 0.878 & 0.079 \\
\hline \multirow[t]{4}{*}{ UTI } & Deviance goodness-of-fit statistic & 2121.826 & 2131.721 \\
\hline & $P$-value & 0.014 & 0.009 \\
\hline & Pearson goodness-of-fit statistic & 2102.839 & 2079.242 \\
\hline & $P$-value & 0.027 & 0.059 \\
\hline \multirow[t]{4}{*}{ Lower UTI } & Deviance goodness-of-fit statistic & 2108.504 & 2168.087 \\
\hline & $P$-value & 0.022 & 0.002 \\
\hline & Pearson goodness-of-fit statistic & 2083.343 & 2103.063 \\
\hline & $P$-value & 0.052 & 0.027 \\
\hline \multirow[t]{4}{*}{ Pyelonephritis } & Deviance goodness-of-fit statistic & 2456.306 & 2257.211 \\
\hline & $P$-value & $<0.001$ & $<0.001$ \\
\hline & Pearson goodness-of-fit statistic & 2159.492 & 1949.885 \\
\hline & $P$-value & 0.003 & 0.681 \\
\hline
\end{tabular}

Poisson regression was used to estimate incidence rate ratios (IRRs) for daily emergency department (ED) and inpatient admissions for renal diseases in relation to an increase in daily maximum temperature per $1^{\circ} \mathrm{C}$ during the warm season (October - March) in Adelaide from 1 July 2003 to 31 March 2014 . Deviance and Pearson goodness-of-fit tests were then applied to assess whether a Poisson model fits the data

The deviance and Pearson goodness-of-fit test show how well a Poisson model fits the data. Each test yields a test statistic, comparing the observed count to the expected count under a Poisson model. The test statistics and degrees of freedom ( $\mathrm{df}$ ) are used to generate P-values. A $P$-value of $<0.05$ indicates a poor fit of the Poisson model - most of the results indicated a poor fit 


\section{Appendix 2}
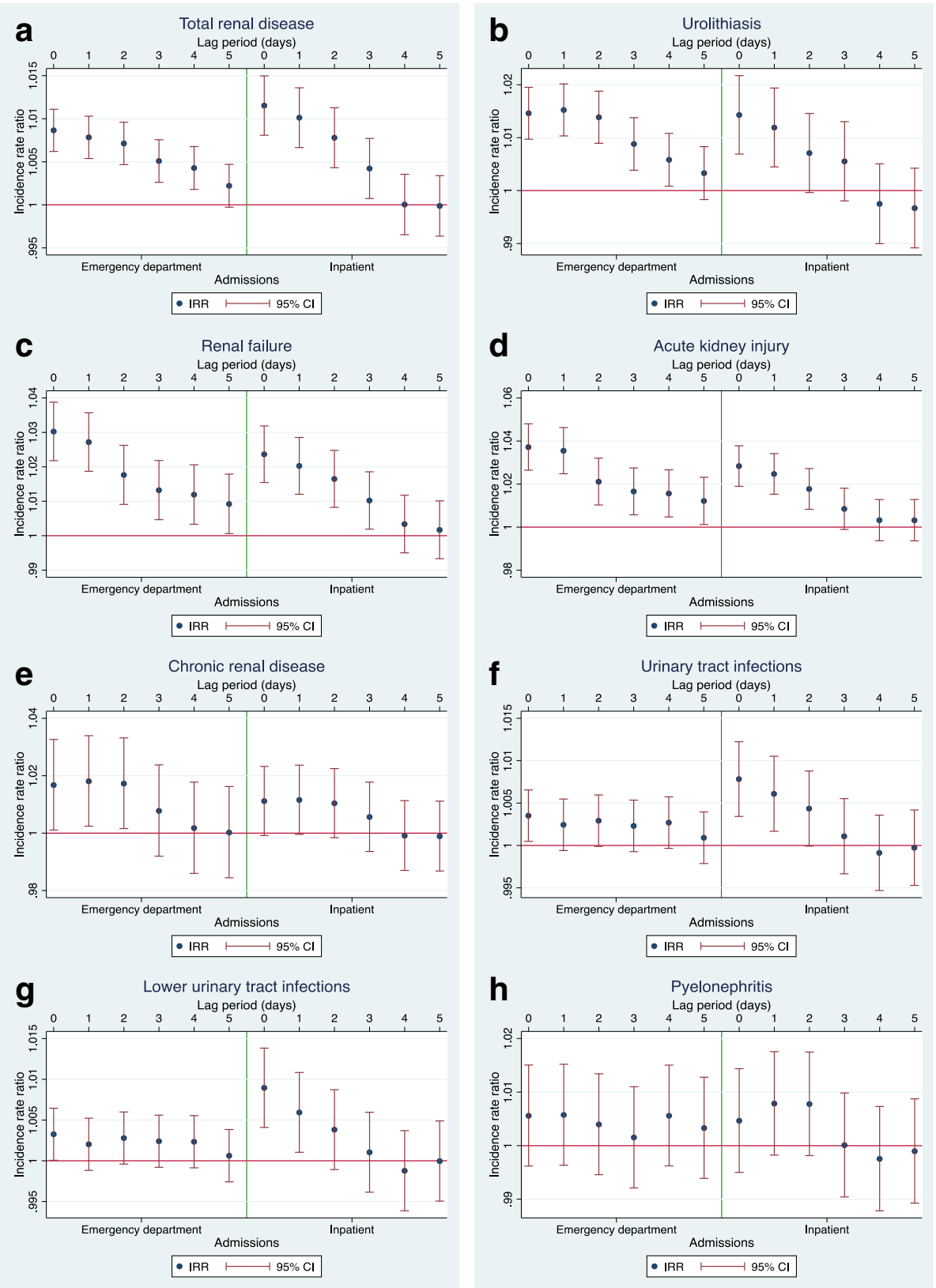

Fig. 7 Incidence rate ratios (IRRs) for renal outcomes and daily minimum temperature for lag periods of $0-5$ days. Graphs for incidence rate ratios (IRRs) for daily admissions for renal diseases and associated $95 \%$ confidence intervals $\left(95 \% \mathrm{Cl}\right.$ ) in relation to daily minimum temperature per $1^{\circ} \mathrm{C}$, during the warm season (October - March) in Adelaide from 1 July 2003 to 31 March 2014. Admissions are listed for each day over a lag period of 0 to 5 days. The left sides of the graphs represent emergency department admissions, and the right sides represent inpatient admissions. Graphs are in relation to (a); total renal disease $(\mathbf{b})$; urolithiasis $(\mathbf{c})$; renal failure $(\mathbf{d})$; acute kidney injury $(\mathbf{e})$; chronic kidney disease $(\mathbf{f})$; urinary tract infections $(\mathbf{g})$; lower urinary tract infections $(\mathbf{h})$; pyelonephritis 
Table 5 Incidence rate ratios (IRRs) for renal outcomes and daily temperature for lag periods (0-5 days)

\begin{tabular}{|c|c|c|c|c|c|c|c|c|}
\hline \multirow{2}{*}{$\frac{\text { Temperature }}{\text { Maximum }}$} & \multirow{2}{*}{$\begin{array}{l}\text { Admission data } \\
\text { ED }\end{array}$} & \multirow{2}{*}{$\begin{array}{l}\text { Disease } \\
\text { Total renal }\end{array}$} & \multirow{2}{*}{$\begin{array}{l}\text { Lag period } \\
0 \text { days }\end{array}$} & \multirow{2}{*}{$\begin{array}{ll}\text { IRR } \\
1.004\end{array}$} & \multicolumn{3}{|l|}{$95 \% \mathrm{Cl}$} & \multirow{2}{*}{$\frac{P \text {-value }}{<0.001}$} \\
\hline & & & & & 1.002 & - & 1.005 & \\
\hline & & disease & 1 day & $\underline{1.006}$ & 1.004 & - & 1.008 & $<0.001$ \\
\hline & & & 2 days & 1.006 & 1.004 & - & 1.008 & $<0.001$ \\
\hline & & & 3 days & 1.005 & 1.003 & - & 1.007 & $<0.001$ \\
\hline & & & 4 days & 1.004 & 1.002 & - & 1.005 & $<0.001$ \\
\hline & & & 5 days & 1.003 & 1.001 & - & 1.005 & 0.001 \\
\hline & & Urolithiasis & 0 days & 1.006 & 1.003 & - & 1.010 & $<0.001$ \\
\hline & & & 1 day & 1.011 & 1.007 & - & 1.014 & $<0.001$ \\
\hline & & & 2 days & 1.011 & 1.008 & - & 1.015 & $<0.001$ \\
\hline & & & 3 days & 1.010 & 1.006 & - & 1.013 & $<0.001$ \\
\hline & & & 4 days & 1.006 & 1.003 & - & 1.010 & $<0.001$ \\
\hline & & & 5 days & 1.004 & 1.001 & - & 1.008 & 0.012 \\
\hline & & Renal failure & 0 days & 1.018 & 1.012 & - & 1.024 & $<0.001$ \\
\hline & & & 1 day & 1.024 & 1.018 & - & 1.030 & $<0.001$ \\
\hline & & & 2 days & 1.018 & 1.011 & - & 1.024 & $<0.001$ \\
\hline & & & 3 days & 1.011 & 1.005 & - & 1.017 & 0.001 \\
\hline & & & 4 days & 1.008 & 1.002 & - & 1.014 & 0.012 \\
\hline & & & 5 days & 1.007 & 1.001 & - & 1.013 & 0.024 \\
\hline & & AKI & 0 days & 1.023 & 1.016 & - & 1.031 & $<0.001$ \\
\hline & & & 1 day & 1.031 & 1.023 & - & 1.039 & $<0.001$ \\
\hline & & & 2 days & 1.023 & 1.015 & - & 1.030 & $<0.001$ \\
\hline & & & 3 days & 1.014 & 1.006 & - & 1.022 & $<0.001$ \\
\hline & & & 4 days & 1.012 & 1.004 & - & 1.020 & 0.002 \\
\hline & & & 5 days & 1.008 & 1.000 & - & 1.016 & 0.047 \\
\hline & & CKD & 0 days & 1.005 & 0.994 & - & 1.016 & 0.365 \\
\hline & & & 1 day & $\underline{1.012}$ & 1.001 & - & 1.024 & 0.03 \\
\hline & & & 2 days & 1.010 & 0.999 & - & 1.021 & 0.085 \\
\hline & & & 3 days & 1.006 & 0.995 & - & 1.018 & 0.263 \\
\hline & & & 4 days & 1.001 & 0.990 & - & 1.013 & 0.802 \\
\hline & & & 5 days & 1.004 & 0.993 & - & 1.016 & 0.447 \\
\hline & & UTI & 0 days & 1.001 & 0.999 & - & 1.003 & 0.411 \\
\hline & & & 1 day & 1.002 & 1.000 & - & 1.004 & 0.042 \\
\hline & & & 2 days & 1.002 & 1.000 & - & 1.004 & 0.043 \\
\hline & & & 3 days & 1.003 & 1.000 & - & 1.005 & 0.02 \\
\hline & & & 4 days & 1.002 & 1.000 & - & 1.004 & 0.114 \\
\hline & & & 5 days & 1.002 & 1.000 & - & 1.004 & 0.08 \\
\hline & & Lower UTI & 0 days & 1.001 & 0.999 & - & 1.003 & 0.507 \\
\hline & & & 1 day & 1.002 & 1.000 & - & 1.004 & 0.078 \\
\hline & & & 2 days & 1.002 & 1.000 & - & 1.004 & 0.094 \\
\hline & & & 3 days & $\underline{1.003}$ & 1.000 & - & 1.005 & 0.018 \\
\hline & & & 4 days & 1.002 & 1.000 & - & 1.004 & 0.081 \\
\hline & & & 5 days & 1.002 & 1.000 & - & 1.004 & 0.086 \\
\hline & & Pyelonephritis & 0 days & 1.002 & 0.995 & - & 1.009 & 0.547 \\
\hline & & & 1 day & 1.004 & 0.997 & - & 1.010 & 0.272 \\
\hline
\end{tabular}


Table 5 Incidence rate ratios (IRRs) for renal outcomes and daily temperature for lag periods (0-5 days) (Continued)

\begin{tabular}{|c|c|c|c|c|c|c|c|c|}
\hline \multirow{5}{*}{\multicolumn{2}{|c|}{ Admission data }} & \multirow[t]{2}{*}{ Disease } & \multirow{2}{*}{$\begin{array}{l}\text { Lag period } \\
2 \text { days }\end{array}$} & \multirow{2}{*}{$\begin{array}{l}\text { IRR } \\
1.005\end{array}$} & \multicolumn{3}{|l|}{$95 \% \mathrm{Cl}$} & \multirow{2}{*}{$\frac{P \text {-value }}{0.184}$} \\
\hline & & & & & 0.998 & - & 1.011 & \\
\hline & & & 3 days & 1.001 & 0.994 & - & 1.008 & 0.761 \\
\hline & & & 4 days & 0.999 & 0.993 & - & 1.006 & 0.868 \\
\hline & & & 5 days & 1.001 & 0.995 & - & 1.008 & 0.682 \\
\hline & \multirow[t]{40}{*}{ Inpatient } & Total renal & 0 days & 1.006 & 1.004 & - & 1.009 & $<0.001$ \\
\hline & & disease & 1 day & 1.007 & 1.005 & - & 1.010 & $<0.001$ \\
\hline & & & 2 days & 1.007 & 1.004 & - & 1.009 & $<0.001$ \\
\hline & & & 3 days & 1.006 & 1.004 & - & 1.009 & $<0.001$ \\
\hline & & & 4 days & 1.003 & 1.000 & - & 1.005 & 0.035 \\
\hline & & & 5 days & 0.999 & 0.997 & - & 1.002 & 0.562 \\
\hline & & Urolithiasis & 0 days & 1.007 & 1.002 & - & 1.012 & 0.009 \\
\hline & & & 1 day & 1.010 & 1.005 & - & 1.015 & $<0.001$ \\
\hline & & & 2 days & 1.011 & 1.006 & - & 1.016 & $<0.001$ \\
\hline & & & 3 days & 1.010 & 1.005 & - & 1.015 & $<0.001$ \\
\hline & & & 4 days & 1.006 & 1.000 & - & 1.011 & 0.04 \\
\hline & & & 5 days & 0.999 & 0.993 & - & 1.004 & 0.631 \\
\hline & & Renal failure & 0 days & $\underline{1.016}$ & 1.010 & - & 1.022 & $<0.001$ \\
\hline & & & 1 day & 1.016 & 1.010 & - & 1.022 & $<0.001$ \\
\hline & & & 2 days & 1.015 & 1.009 & - & 1.021 & $<0.001$ \\
\hline & & & 3 days & 1.014 & 1.008 & - & 1.020 & $<0.001$ \\
\hline & & & 4 days & 1.007 & 1.001 & - & 1.013 & 0.015 \\
\hline & & & 5 days & 1.000 & 0.994 & - & 1.006 & 0.993 \\
\hline & & AKI & 0 days & 1.020 & 1.013 & - & 1.026 & $<0.001$ \\
\hline & & & 1 day & $\underline{1.021}$ & 1.014 & - & 1.027 & $<0.001$ \\
\hline & & & 2 days & 1.018 & 1.011 & - & 1.025 & $<0.001$ \\
\hline & & & 3 days & 1.014 & 1.007 & - & 1.020 & $<0.001$ \\
\hline & & & 4 days & 1.007 & 1.001 & - & 1.014 & 0.034 \\
\hline & & & 5 days & 1.000 & 0.994 & - & 1.007 & 0.955 \\
\hline & & CKD & 0 days & 1.006 & 0.997 & - & 1.014 & 0.171 \\
\hline & & & 1 day & 1.005 & 0.997 & - & 1.014 & 0.208 \\
\hline & & & 2 days & 1.009 & 1.000 & - & 1.018 & 0.042 \\
\hline & & & 3 days & 1.010 & 1.001 & - & 1.018 & 0.023 \\
\hline & & & 4 days & 1.003 & 0.995 & - & 1.012 & 0.449 \\
\hline & & & 5 days & 0.996 & 0.987 & - & 1.004 & 0.317 \\
\hline & & UTI & 0 days & 1.004 & 1.001 & - & 1.008 & 0.005 \\
\hline & & & 1 day & 1.005 & 1.001 & - & 1.008 & 0.004 \\
\hline & & & 2 days & 1.004 & 1.000 & - & 1.007 & 0.027 \\
\hline & & & 3 days & 1.003 & 1.000 & - & 1.006 & 0.044 \\
\hline & & & 4 days & 1.000 & 0.997 & - & 1.003 & 0.908 \\
\hline & & & 5 days & 0.999 & 0.996 & - & 1.002 & 0.548 \\
\hline & & Lower UTI & 0 days & 1.005 & 1.002 & - & 1.009 & 0.002 \\
\hline & & & 1 day & 1.005 & 1.002 & - & 1.009 & 0.002 \\
\hline & & & 2 days & 1.004 & 1.000 & - & 1.007 & 0.028 \\
\hline & & & 3 days & 1.003 & 1.000 & - & 1.007 & 0.055 \\
\hline
\end{tabular}


Table 5 Incidence rate ratios (IRRs) for renal outcomes and daily temperature for lag periods (0-5 days) (Continued)

\begin{tabular}{|c|c|c|c|c|c|c|c|c|}
\hline \multirow[t]{2}{*}{ Temperature } & \multirow[t]{2}{*}{ Admission data } & \multirow[t]{2}{*}{ Disease } & \multirow{2}{*}{$\frac{\text { Lag period }}{4 \text { days }}$} & \multirow{2}{*}{$\begin{array}{l}\text { IRR } \\
1.000\end{array}$} & \multicolumn{3}{|l|}{$95 \% \mathrm{Cl}$} & \multirow{2}{*}{$\frac{P \text {-value }}{0.866}$} \\
\hline & & & & & 0.997 & - & 1.004 & \\
\hline & & & 5 days & 0.999 & 0.996 & - & 1.003 & 0.608 \\
\hline & & Pyelonephritis & 0 days & 1.002 & 0.996 & - & 1.009 & 0.472 \\
\hline & & & 1 day & 1.003 & 0.996 & - & 1.009 & 0.47 \\
\hline & & & 2 days & 1.004 & 0.997 & - & 1.010 & 0.314 \\
\hline & & & 3 days & 1.004 & 0.997 & - & 1.010 & 0.307 \\
\hline & & & 4 days & 0.999 & 0.993 & - & 1.006 & 0.864 \\
\hline & & & 5 days & 0.997 & 0.990 & - & 1.004 & 0.386 \\
\hline \multirow[t]{36}{*}{ Minimum } & $\mathrm{ED}$ & Total renal & $\underline{0 \text { days }}$ & 1.009 & 1.006 & - & 1.011 & $<0.001$ \\
\hline & & disease & 1 day & 1.008 & 1.005 & - & 1.010 & $<0.001$ \\
\hline & & & 2 days & 1.007 & 1.005 & - & 1.010 & $<0.001$ \\
\hline & & & 3 days & 1.005 & 1.003 & - & 1.008 & $<0.001$ \\
\hline & & & 4 days & 1.004 & 1.002 & - & 1.007 & 0.001 \\
\hline & & & 5 days & 1.002 & 1.000 & - & 1.005 & 0.082 \\
\hline & & Urolithiasis & 0 days & 1.015 & 1.010 & - & 1.020 & $<0.001$ \\
\hline & & & 1 day & $\underline{1.015}$ & 1.010 & - & 1.020 & $<0.001$ \\
\hline & & & 2 days & 1.014 & 1.009 & - & 1.019 & $<0.001$ \\
\hline & & & 3 days & 1.009 & 1.004 & - & 1.014 & $<0.001$ \\
\hline & & & 4 days & 1.006 & 1.001 & - & 1.011 & 0.022 \\
\hline & & & 5 days & 1.003 & 0.998 & - & 1.008 & 0.196 \\
\hline & & Renal failure & $\underline{0 \text { days }}$ & $\underline{1.030}$ & 1.022 & - & 1.039 & $<0.001$ \\
\hline & & & 1 day & 1.027 & 1.019 & - & 1.036 & $<0.001$ \\
\hline & & & 2 days & 1.018 & 1.009 & - & 1.026 & $<0.001$ \\
\hline & & & 3 days & 1.013 & 1.005 & - & 1.022 & 0.002 \\
\hline & & & 4 days & 1.012 & 1.003 & - & 1.021 & 0.006 \\
\hline & & & 5 days & 1.009 & 1.001 & - & 1.018 & 0.036 \\
\hline & & AKI & $\underline{0 \text { days }}$ & $\underline{1.037}$ & 1.026 & - & 1.048 & $<0.001$ \\
\hline & & & 1 day & 1.035 & 1.025 & - & 1.046 & $<0.001$ \\
\hline & & & 2 days & 1.021 & 1.010 & - & 1.032 & $<0.001$ \\
\hline & & & 3 days & 1.017 & 1.006 & - & 1.027 & 0.003 \\
\hline & & & 4 days & 1.016 & 1.005 & - & 1.027 & 0.005 \\
\hline & & & 5 days & 1.012 & 1.001 & - & 1.023 & 0.029 \\
\hline & & CKD & 0 days & 1.017 & 1.001 & - & 1.033 & 0.036 \\
\hline & & & 1 day & 1.018 & 1.002 & - & 1.034 & 0.024 \\
\hline & & & 2 days & 1.017 & 1.002 & - & 1.033 & 0.031 \\
\hline & & & 3 days & 1.008 & 0.992 & - & 1.024 & 0.338 \\
\hline & & & 4 days & 1.002 & 0.986 & - & 1.018 & 0.83 \\
\hline & & & 5 days & 1.000 & 0.984 & - & 1.016 & 0.98 \\
\hline & & UTI & 0 days & 1.004 & 1.000 & - & 1.007 & 0.023 \\
\hline & & & 1 day & 1.002 & 0.999 & - & 1.005 & 0.116 \\
\hline & & & 2 days & 1.003 & 1.000 & - & 1.006 & 0.06 \\
\hline & & & 3 days & 1.002 & 0.999 & - & 1.005 & 0.138 \\
\hline & & & 4 days & 1.003 & 1.000 & - & 1.006 & 0.082 \\
\hline & & & 5 days & 1.001 & 0.998 & - & 1.004 & 0.562 \\
\hline
\end{tabular}


Table 5 Incidence rate ratios (IRRs) for renal outcomes and daily temperature for lag periods (0-5 days) (Continued)

\begin{tabular}{|c|c|c|c|c|c|c|c|c|}
\hline \multirow[t]{2}{*}{ Temperature } & \multirow[t]{2}{*}{ Admission data } & \multirow{2}{*}{$\begin{array}{l}\text { Disease } \\
\text { Lower UTI }\end{array}$} & \multirow{2}{*}{$\begin{array}{l}\text { Lag period } \\
0 \text { days }\end{array}$} & \multirow{2}{*}{$\begin{array}{l}\text { IRR } \\
1.003 \\
\end{array}$} & \multicolumn{3}{|l|}{$95 \% \mathrm{Cl}$} & \multirow{2}{*}{$\frac{P \text {-value }}{0.045}$} \\
\hline & & & & & 1.000 & - & 1.006 & \\
\hline & & & 1 day & 1.002 & 0.999 & - & 1.005 & 0.216 \\
\hline & & & 2 days & 1.003 & 1.000 & - & 1.006 & 0.087 \\
\hline & & & 3 days & 1.002 & 0.999 & - & 1.006 & 0.142 \\
\hline & & & 4 days & 1.002 & 0.999 & - & 1.006 & 0.153 \\
\hline & & & 5 days & 1.001 & 0.997 & - & 1.004 & 0.706 \\
\hline & & Pyelonephritis & 0 days & 1.006 & 0.996 & - & 1.015 & 0.245 \\
\hline & & & 1 day & 1.006 & 0.996 & - & 1.015 & 0.232 \\
\hline & & & 2 days & 1.004 & 0.995 & - & 1.013 & 0.41 \\
\hline & & & 3 days & 1.002 & 0.992 & - & 1.011 & 0.752 \\
\hline & & & 4 days & 1.006 & 0.996 & - & 1.015 & 0.244 \\
\hline & & & 5 days & 1.003 & 0.994 & - & 1.013 & 0.495 \\
\hline & \multirow[t]{32}{*}{ Inpatient } & Total renal & 0 days & 1.012 & 1.008 & - & 1.015 & $<0.001$ \\
\hline & & disease & 1 day & 1.010 & 1.007 & - & 1.014 & $<0.001$ \\
\hline & & & 2 days & 1.008 & 1.004 & - & 1.011 & $<0.001$ \\
\hline & & & 3 days & 1.004 & 1.001 & - & 1.008 & 0.018 \\
\hline & & & 4 days & 1.000 & 0.997 & - & 1.004 & 0.987 \\
\hline & & & 5 days & 1.000 & 0.996 & - & 1.003 & 0.942 \\
\hline & & Urolithiasis & 0 days & 1.014 & 1.007 & - & 1.022 & $<0.001$ \\
\hline & & & 1 day & 1.012 & 1.004 & - & 1.019 & 0.002 \\
\hline & & & 2 days & 1.007 & 1.000 & - & 1.015 & 0.062 \\
\hline & & & 3 days & 1.006 & 0.998 & - & 1.013 & 0.147 \\
\hline & & & 4 days & 0.997 & 0.990 & - & 1.005 & 0.514 \\
\hline & & & 5 days & 0.997 & 0.989 & - & 1.004 & 0.39 \\
\hline & & Renal failure & $\underline{0 \text { days }}$ & 1.024 & 1.015 & - & 1.032 & $<0.001$ \\
\hline & & & 1 day & 1.020 & 1.012 & - & 1.029 & $<0.001$ \\
\hline & & & 2 days & 1.016 & 1.008 & - & 1.025 & $<0.001$ \\
\hline & & & 3 days & 1.010 & 1.002 & - & 1.019 & 0.016 \\
\hline & & & 4 days & 1.003 & 0.995 & - & 1.012 & 0.431 \\
\hline & & & 5 days & 1.002 & 0.993 & - & 1.010 & 0.695 \\
\hline & & AKI & 0 days & 1.028 & 1.019 & - & 1.038 & $<0.001$ \\
\hline & & & 1 day & 1.025 & 1.015 & - & 1.034 & $<0.001$ \\
\hline & & & 2 days & 1.018 & 1.008 & - & 1.027 & $<0.001$ \\
\hline & & & 3 days & 1.008 & 0.999 & - & 1.018 & 0.082 \\
\hline & & & 4 days & 1.003 & 0.994 & - & 1.013 & 0.513 \\
\hline & & & 5 days & 1.003 & 0.994 & - & 1.013 & 0.521 \\
\hline & & CKD & 0 days & 1.011 & 0.999 & - & 1.023 & 0.068 \\
\hline & & & 1 day & 1.012 & 1.000 & - & 1.024 & 0.059 \\
\hline & & & 2 days & 1.010 & 0.998 & - & 1.022 & 0.089 \\
\hline & & & 3 days & 1.006 & 0.994 & - & 1.018 & 0.361 \\
\hline & & & 4 days & 0.999 & 0.987 & - & 1.011 & 0.884 \\
\hline & & & 5 days & 0.999 & 0.987 & - & 1.011 & 0.859 \\
\hline & & UTI & $\underline{0 \text { days }}$ & 1.008 & 1.003 & - & 1.012 & $<0.001$ \\
\hline & & & 1 day & 1.006 & 1.002 & - & 1.011 & 0.007 \\
\hline
\end{tabular}


Table 5 Incidence rate ratios (IRRs) for renal outcomes and daily temperature for lag periods (0-5 days) (Continued)

\begin{tabular}{|c|c|c|c|c|c|c|c|c|}
\hline \multirow[t]{2}{*}{ Temperature } & \multirow[t]{2}{*}{ Admission data } & \multirow[t]{2}{*}{ Disease } & \multirow{2}{*}{$\frac{\text { Lag period }}{2 \text { days }}$} & \multirow{2}{*}{$\frac{\mathrm{IRR}}{1.004}$} & \multicolumn{3}{|l|}{$95 \% \mathrm{Cl}$} & \multirow{2}{*}{$\frac{P \text {-value }}{0.054}$} \\
\hline & & & & & 1.000 & - & 1.009 & \\
\hline & & & 3 days & 1.001 & 0.997 & - & 1.006 & 0.633 \\
\hline & & & 4 days & 0.999 & 0.995 & - & 1.004 & 0.698 \\
\hline & & & 5 days & 1.000 & 0.995 & - & 1.004 & 0.903 \\
\hline & & Lower UTI & 0 days & 1.009 & 1.004 & - & 1.014 & $<0.001$ \\
\hline & & & 1 day & 1.006 & 1.001 & - & 1.011 & 0.017 \\
\hline & & & 2 days & 1.004 & 0.999 & - & 1.009 & 0.126 \\
\hline & & & 3 days & 1.001 & 0.996 & - & 1.006 & 0.677 \\
\hline & & & 4 days & 0.999 & 0.994 & - & 1.004 & 0.624 \\
\hline & & & 5 days & 1.000 & 0.995 & - & 1.005 & 0.986 \\
\hline & & Pyelonephritis & 0 days & 1.005 & 0.995 & - & 1.014 & 0.346 \\
\hline & & & 1 day & 1.008 & 0.998 & - & 1.018 & 0.11 \\
\hline & & & 2 days & 1.008 & 0.998 & - & 1.017 & 0.114 \\
\hline & & & 3 days & 1.000 & 0.990 & - & 1.010 & 0.986 \\
\hline & & & 4 days & 0.998 & 0.988 & - & 1.007 & 0.62 \\
\hline & & & 5 days & 0.999 & 0.989 & - & 1.009 & 0.833 \\
\hline \multirow[t]{28}{*}{ Average } & ED & Total renal & 0 days & 1.007 & 1.004 & - & 1.009 & $<0.001$ \\
\hline & & disease & 1 day & 1.009 & 1.006 & - & 1.011 & $<0.001$ \\
\hline & & & 2 days & 1.008 & 1.006 & - & 1.010 & $<0.001$ \\
\hline & & & 3 days & 1.007 & 1.004 & - & 1.009 & $<0.001$ \\
\hline & & & 4 days & 1.005 & 1.003 & - & 1.007 & $<0.001$ \\
\hline & & & 5 days & 1.004 & 1.001 & - & 1.006 & 0.002 \\
\hline & & Urolithiasis & 0 days & 1.012 & 1.007 & - & 1.016 & $<0.001$ \\
\hline & & & 1 day & 1.015 & 1.011 & - & 1.020 & $<0.001$ \\
\hline & & & 2 days & 1.016 & 1.011 & - & 1.020 & $<0.001$ \\
\hline & & & 3 days & 1.012 & 1.007 & - & 1.016 & $<0.001$ \\
\hline & & & 4 days & 1.008 & 1.003 & - & 1.012 & 0.001 \\
\hline & & & 5 days & 1.005 & 1.001 & - & 1.010 & 0.024 \\
\hline & & Renal failure & 0 days & 1.028 & 1.020 & - & 1.036 & $<0.001$ \\
\hline & & & 1 day & 1.032 & 1.024 & - & 1.040 & $<0.001$ \\
\hline & & & 2 days & 1.022 & 1.014 & - & 1.030 & $<0.001$ \\
\hline & & & 3 days & 1.014 & 1.007 & - & 1.022 & $<0.001$ \\
\hline & & & 4 days & 1.012 & 1.004 & - & 1.020 & 0.004 \\
\hline & & & 5 days & 1.010 & 1.002 & - & 1.018 & 0.015 \\
\hline & & AKI & 0 days & 1.035 & 1.025 & - & 1.045 & $<0.001$ \\
\hline & & & 1 day & 1.041 & 1.031 & - & 1.051 & $<0.001$ \\
\hline & & & 2 days & 1.028 & 1.018 & - & 1.038 & $<0.001$ \\
\hline & & & 3 days & 1.019 & 1.009 & - & 1.029 & $<0.001$ \\
\hline & & & 4 days & 1.017 & 1.007 & - & 1.027 & 0.001 \\
\hline & & & 5 days & 1.012 & 1.002 & - & 1.022 & 0.021 \\
\hline & & CKD & 0 days & 1.011 & 0.997 & - & 1.026 & 0.125 \\
\hline & & & 1 day & 1.018 & 1.004 & - & 1.033 & 0.014 \\
\hline & & & 2 days & 1.016 & 1.001 & - & 1.030 & 0.034 \\
\hline & & & 3 days & 1.009 & 0.994 & - & 1.023 & 0.248 \\
\hline
\end{tabular}


Table 5 Incidence rate ratios (IRRs) for renal outcomes and daily temperature for lag periods (0-5 days) (Continued)

\begin{tabular}{|c|c|c|c|c|c|c|c|c|}
\hline \multirow[t]{2}{*}{ Temperature } & \multirow[t]{2}{*}{ Admission data } & \multirow[t]{2}{*}{ Disease } & \multirow{2}{*}{$\begin{array}{l}\text { Lag period } \\
4 \text { days }\end{array}$} & \multirow{2}{*}{$\begin{array}{l}\text { IRR } \\
1.002\end{array}$} & \multicolumn{3}{|l|}{$95 \% \mathrm{Cl}$} & \multirow{2}{*}{$\frac{P \text {-value }}{0.784}$} \\
\hline & & & & & 0.987 & - & 1.017 & \\
\hline & & & 5 days & 1.004 & 0.989 & - & 1.018 & 0.621 \\
\hline & & UTI & 0 days & 1.002 & 0.999 & - & 1.005 & 0.121 \\
\hline & & & 1 day & 1.003 & 1.000 & - & 1.006 & 0.041 \\
\hline & & & 2 days & 1.003 & 1.000 & - & 1.006 & 0.03 \\
\hline & & & 3 days & $\underline{1.003}$ & 1.000 & - & 1.006 & 0.028 \\
\hline & & & 4 days & 1.003 & 1.000 & - & 1.005 & 0.063 \\
\hline & & & 5 days & 1.002 & 0.999 & - & 1.005 & 0.165 \\
\hline & & Lower UTI & 0 days & 1.002 & 0.999 & - & 1.005 & 0.184 \\
\hline & & & 1 day & 1.003 & 1.000 & - & 1.006 & 0.085 \\
\hline & & & 2 days & 1.003 & 1.000 & - & 1.006 & 0.063 \\
\hline & & & 3 days & $\underline{1.003}$ & 1.000 & - & 1.006 & 0.026 \\
\hline & & & 4 days & 1.003 & 1.000 & - & 1.006 & 0.068 \\
\hline & & & 5 days & 1.002 & 0.999 & - & 1.005 & 0.203 \\
\hline & & Pyelonephritis & 0 days & 1.004 & 0.995 & - & 1.013 & 0.364 \\
\hline & & & 1 day & 1.006 & 0.997 & - & 1.014 & 0.207 \\
\hline & & & 2 days & 1.005 & 0.997 & - & 1.014 & 0.215 \\
\hline & & & 3 days & 1.002 & 0.993 & - & 1.010 & 0.732 \\
\hline & & & 4 days & 1.002 & 0.993 & - & 1.011 & 0.67 \\
\hline & & & 5 days & 1.003 & 0.994 & - & 1.011 & 0.564 \\
\hline & \multirow[t]{24}{*}{ Inpatient } & Total renal & 0 days & 1.010 & 1.007 & - & 1.013 & $<0.001$ \\
\hline & & disease & 1 day & $\underline{1.011}$ & 1.007 & - & 1.014 & $<0.001$ \\
\hline & & & 2 days & 1.009 & 1.006 & - & 1.012 & $<0.001$ \\
\hline & & & 3 days & 1.007 & 1.004 & - & 1.010 & $<0.001$ \\
\hline & & & 4 days & 1.002 & 0.999 & - & 1.005 & 0.171 \\
\hline & & & 5 days & 0.999 & 0.996 & - & 1.003 & 0.689 \\
\hline & & Urolithiasis & 0 days & 1.012 & 1.005 & - & 1.019 & 0.001 \\
\hline & & & 1 day & $\underline{1.013}$ & 1.007 & - & 1.020 & $<0.001$ \\
\hline & & & 2 days & 1.012 & 1.005 & - & 1.019 & $<0.001$ \\
\hline & & & 3 days & 1.011 & 1.004 & - & 1.018 & 0.002 \\
\hline & & & 4 days & 1.004 & 0.997 & - & 1.011 & 0.297 \\
\hline & & & 5 days & 0.998 & 0.991 & - & 1.004 & 0.483 \\
\hline & & Renal failure & 0 days & 1.023 & 1.016 & - & 1.031 & $<0.001$ \\
\hline & & & 1 day & 1.022 & 1.014 & - & 1.029 & $<0.001$ \\
\hline & & & 2 days & 1.019 & 1.012 & - & 1.027 & $<0.001$ \\
\hline & & & 3 days & 1.016 & 1.008 & - & 1.024 & $<0.001$ \\
\hline & & & 4 days & 1.008 & 1.000 & - & 1.015 & 0.053 \\
\hline & & & 5 days & 1.001 & 0.993 & - & 1.008 & 0.864 \\
\hline & & AKI & $\underline{0 \text { days }}$ & $\underline{1.029}$ & 1.020 & - & 1.037 & $<0.001$ \\
\hline & & & 1 day & 1.028 & 1.019 & - & 1.036 & $<0.001$ \\
\hline & & & 2 days & 1.022 & 1.014 & - & 1.031 & $<0.001$ \\
\hline & & & 3 days & 1.015 & 1.006 & - & 1.024 & 0.001 \\
\hline & & & 4 days & 1.007 & 0.999 & - & 1.016 & 0.096 \\
\hline & & & 5 days & 1.001 & 0.993 & - & 1.010 & 0.751 \\
\hline
\end{tabular}


Table 5 Incidence rate ratios (IRRs) for renal outcomes and daily temperature for lag periods (0-5 days) (Continued)

\begin{tabular}{|c|c|c|c|c|c|c|c|c|}
\hline \multirow[t]{2}{*}{ Temperature } & \multirow[t]{2}{*}{ Admission data } & \multirow{2}{*}{$\begin{array}{l}\text { Disease } \\
C K D\end{array}$} & \multirow{2}{*}{$\begin{array}{l}\text { Lag period } \\
0 \text { days }\end{array}$} & \multirow{2}{*}{$\frac{\text { IRR }}{1.010}$} & \multicolumn{3}{|l|}{$95 \% \mathrm{Cl}$} & \multirow{2}{*}{$\frac{P \text {-value }}{0.087}$} \\
\hline & & & & & 0.999 & - & 1.021 & \\
\hline & & & 1 day & 1.010 & 0.998 & - & 1.021 & 0.092 \\
\hline & & & 2 days & 1.012 & 1.001 & - & 1.023 & 0.037 \\
\hline & & & 3 days & 1.011 & 1.000 & - & 1.022 & 0.058 \\
\hline & & & 4 days & 1.002 & 0.991 & - & 1.014 & 0.679 \\
\hline & & & 5 days & 0.996 & 0.985 & - & 1.007 & 0.466 \\
\hline & & UTI & 0 days & 1.007 & 1.003 & - & 1.011 & 0.001 \\
\hline & & & 1 day & 1.006 & 1.002 & - & 1.010 & 0.002 \\
\hline & & & 2 days & 1.005 & 1.001 & - & 1.009 & 0.02 \\
\hline & & & 3 days & 1.003 & 0.999 & - & 1.007 & 0.129 \\
\hline & & & 4 days & 1.000 & 0.996 & - & 1.004 & 0.906 \\
\hline & & & 5 days & 0.999 & 0.995 & - & 1.003 & 0.663 \\
\hline & & Lower UTI & 0 days & 1.008 & 1.004 & - & 1.013 & $<0.001$ \\
\hline & & & 1 day & 1.007 & 1.003 & - & 1.012 & 0.002 \\
\hline & & & 2 days & 1.005 & 1.000 & - & 1.009 & 0.033 \\
\hline & & & 3 days & 1.003 & 0.999 & - & 1.008 & 0.154 \\
\hline & & & 4 days & 1.000 & 0.995 & - & 1.004 & 0.901 \\
\hline & & & 5 days & 0.999 & 0.995 & - & 1.004 & 0.735 \\
\hline & & Pyelonephritis & 0 days & 1.004 & 0.995 & - & 1.013 & 0.378 \\
\hline & & & 1 day & 1.005 & 0.997 & - & 1.014 & 0.229 \\
\hline & & & 2 days & 1.006 & 0.997 & - & 1.015 & 0.168 \\
\hline & & & 3 days & 1.003 & 0.994 & - & 1.012 & 0.501 \\
\hline & & & 4 days & 0.998 & 0.990 & - & 1.007 & 0.724 \\
\hline & & & 5 days & 0.997 & 0.988 & - & 1.006 & 0.526 \\
\hline
\end{tabular}

Estimated incidence rate ratios (IRRs) and associated $95 \%$ confidence intervals and $P$-values for daily admissions for renal diseases in relation to an increase in daily maximum temperature per $1^{\circ} \mathrm{C}$ over lag 0-5 days during the warm seasons (October - March) in Adelaide from 1 July 2003 to 31 March 2014. Both emergency department (ED) and inpatient admissions were included. The associated lag periods with the highest IRR value (rounded to 3 decimal figures) and are statistically significant are underlined 


\section{Appendix 3}

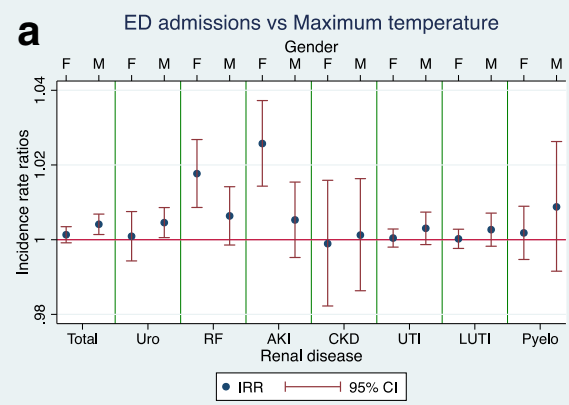

\section{b Inpatient admissions vs Maximum temperature}

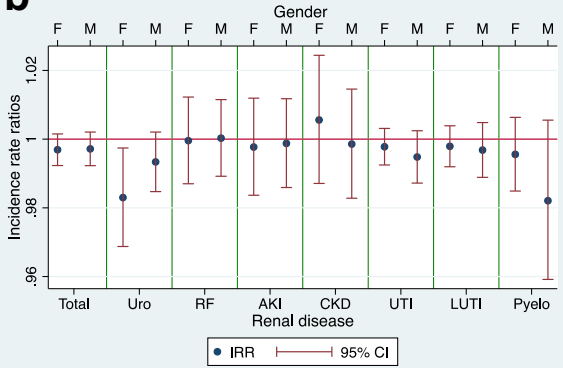

C ED admissions vs Minimum temperature

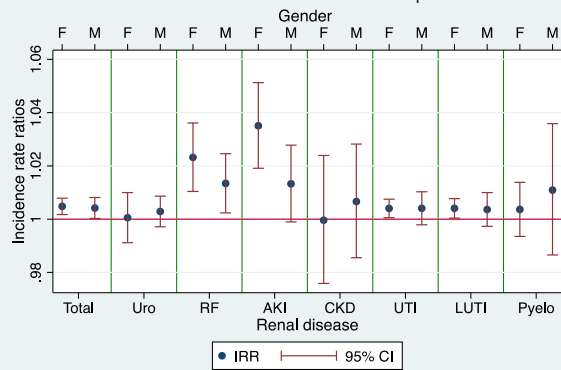

d Inpatient admissions vs Minimum temperature
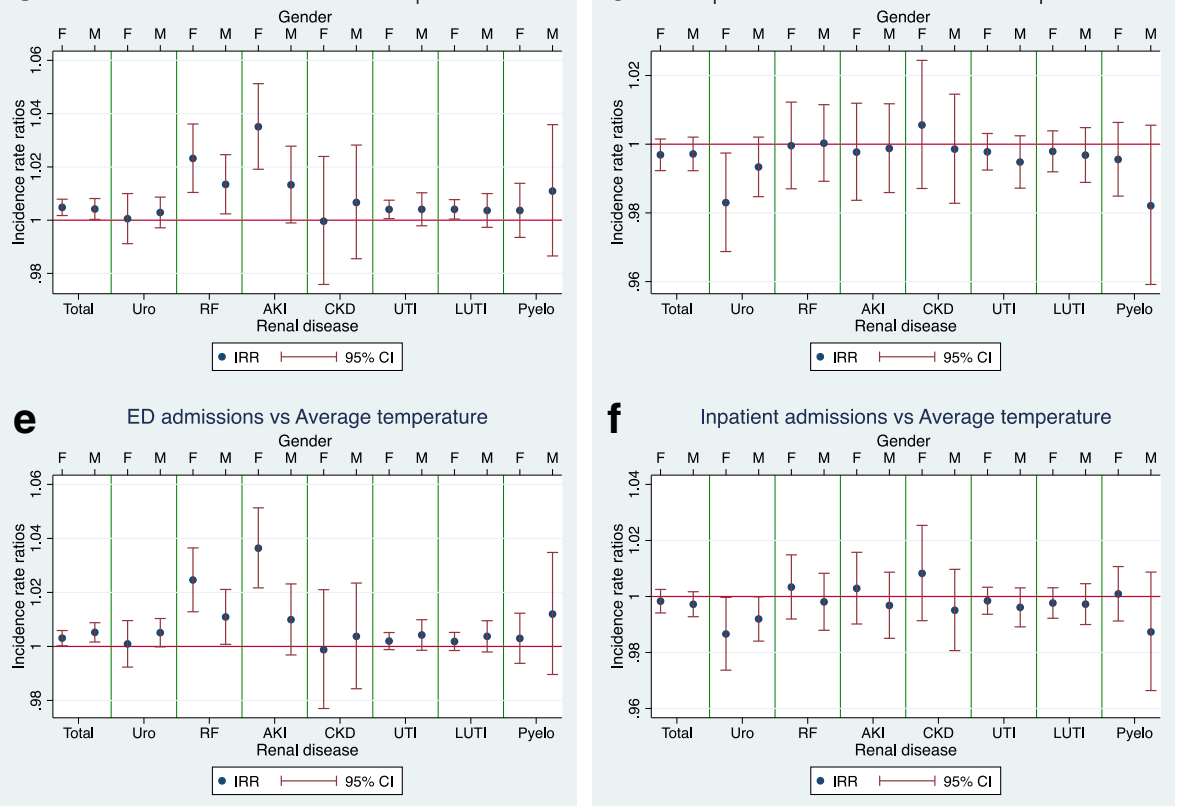

Fig. 8 Incidence rate ratios (IRRs) for renal admissions and daily temperature stratified by gender. Graphs for incidence rate ratios (IRRs) for daily admissions for renal diseases and associated $95 \%$ confidence intervals $(95 \% \mathrm{Cl})$ in relation to daily temperature per $1^{\circ} \mathrm{C}$, during the warm season (October - March) in Adelaide from 1 July 2003 to 31 March 2014. Results are shown for females (F) and males (M) separately. Graphs (a), (c) and (e) represent emergency department (ED) admissions, and graphs (b), (d) and (f) represent inpatient admissions. The temperature measures shown are maximum $((\mathbf{a})$ and $(\mathbf{b}))$, minimum $((\mathbf{c})$ and $(\mathbf{d}))$ and average $((\mathbf{e})$ and $(\mathbf{f})$ ). The renal categories are: total renal disease (Total); urolithiasis (Uro); renal failure (RF); acute kidney injury (AKI); chronic kidney disease (CKD); urinary tract infections (UTI); lower urinary tract infections (LUTI); pyelonephritis (Pyelo) 
Table 6 Incidence rate ratios (IRRs) for renal outcomes and daily temperature stratified by gender

\begin{tabular}{|c|c|c|c|c|c|c|c|c|}
\hline \multirow{2}{*}{$\frac{\text { Temperature }}{\text { Maximum }}$} & \multirow{2}{*}{$\begin{array}{l}\text { Admission data } \\
\text { ED }\end{array}$} & \multirow{2}{*}{$\begin{array}{l}\text { Disease } \\
\text { Total renal disease }\end{array}$} & \multirow{2}{*}{$\begin{array}{l}\text { Gender } \\
\mathrm{F}\end{array}$} & \multirow{2}{*}{$\frac{\mid \mathrm{IRR}}{1.001}$} & \multicolumn{3}{|c|}{$95 \% \mathrm{Cl}$} & \multirow{2}{*}{$\frac{P \text {-value }}{0.231}$} \\
\hline & & & & & 0.999 & - & 1.003 & \\
\hline & & & M & 1.004 & 1.001 & - & 1.007 & 0.003 \\
\hline & & Urolithiasis & $\mathrm{F}$ & 1.001 & 0.994 & - & 1.008 & 0.788 \\
\hline & & & M & 1.005 & 1.001 & - & 1.009 & 0.026 \\
\hline & & Renal failure & $\mathrm{F}$ & 1.018 & 1.009 & - & 1.027 & $<0.001$ \\
\hline & & & M & 1.006 & 0.999 & - & 1.014 & 0.109 \\
\hline & & AKI & $\mathrm{F}$ & 1.026 & 1.014 & - & 1.037 & $<0.001$ \\
\hline & & & M & 1.005 & 0.995 & - & 1.015 & 0.305 \\
\hline & & CKD & $\mathrm{F}$ & 0.999 & 0.982 & - & 1.016 & 0.902 \\
\hline & & & M & 1.001 & 0.986 & - & 1.016 & 0.873 \\
\hline & & UTI & $\mathrm{F}$ & 1.000 & 0.998 & - & 1.003 & 0.733 \\
\hline & & & M & 1.003 & 0.999 & - & 1.007 & 0.169 \\
\hline & & Lower UTI & $\mathrm{F}$ & 1.000 & 0.998 & - & 1.003 & 0.863 \\
\hline & & & M & 1.003 & 0.998 & - & 1.007 & 0.237 \\
\hline & & Pyelonephritis & $\mathrm{F}$ & 1.002 & 0.995 & - & 1.009 & 0.619 \\
\hline & & & M & 1.009 & 0.992 & & 1.026 & 0.319 \\
\hline \multirow[t]{16}{*}{ Minimum } & ED & Total renal disease & $\mathrm{F}$ & 1.005 & 1.002 & - & 1.008 & 0.002 \\
\hline & & & M & 1.004 & 1.000 & - & 1.008 & 0.036 \\
\hline & & Urolithiasis & $\mathrm{F}$ & 1.001 & 0.991 & - & 1.010 & 0.912 \\
\hline & & & M & 1.003 & 0.997 & - & 1.009 & 0.327 \\
\hline & & Renal failure & $\mathrm{F}$ & 1.023 & 1.010 & - & 1.036 & $<0.001$ \\
\hline & & & M & 1.013 & 1.002 & - & 1.025 & 0.017 \\
\hline & & AKI & $\mathrm{F}$ & 1.035 & 1.019 & - & 1.051 & $<0.001$ \\
\hline & & & M & 1.013 & 0.999 & - & 1.028 & 0.069 \\
\hline & & CKD & $\mathrm{F}$ & 1.000 & 0.976 & - & 1.024 & 0.974 \\
\hline & & & M & 1.007 & 0.985 & - & 1.028 & 0.542 \\
\hline & & UTI & $\mathrm{F}$ & 1.004 & 1.001 & - & 1.007 & 0.022 \\
\hline & & & M & 1.004 & 0.998 & - & 1.010 & 0.199 \\
\hline & & Lower UTI & $\mathrm{F}$ & 1.004 & 1.000 & - & 1.008 & 0.029 \\
\hline & & & M & 1.004 & 0.997 & - & 1.010 & 0.262 \\
\hline & & Pyelonephritis & $\mathrm{F}$ & 1.004 & 0.994 & & 1.014 & 0.481 \\
\hline & & & M & 1.011 & 0.987 & - & 1.036 & 0.383 \\
\hline \multirow[t]{12}{*}{ Average } & ED & Total renal disease & $\mathrm{F}$ & 1.003 & 1.000 & - & 1.006 & 0.032 \\
\hline & & & M & 1.005 & 1.002 & - & 1.009 & 0.004 \\
\hline & & Urolithiasis & $\mathrm{F}$ & 1.001 & 0.992 & - & 1.010 & 0.834 \\
\hline & & & M & 1.005 & 1.000 & - & 1.010 & 0.057 \\
\hline & & Renal failure & $\mathrm{F}$ & 1.025 & 1.013 & - & 1.037 & $<0.001$ \\
\hline & & & M & 1.011 & 1.001 & - & 1.021 & 0.034 \\
\hline & & AKI & $\mathrm{F}$ & 1.036 & 1.022 & - & 1.051 & $<0.001$ \\
\hline & & & M & 1.010 & 0.997 & - & 1.023 & 0.138 \\
\hline & & CKD & $\mathrm{F}$ & 0.999 & 0.977 & - & 1.021 & 0.913 \\
\hline & & & M & 1.004 & 0.984 & - & 1.023 & 0.708 \\
\hline & & UTI & $\mathrm{F}$ & 1.002 & 0.999 & - & 1.005 & 0.218 \\
\hline & & & M & 1.004 & 0.999 & - & 1.010 & 0.143 \\
\hline
\end{tabular}


Table 6 Incidence rate ratios (IRRs) for renal outcomes and daily temperature stratified by gender (Continued)

\begin{tabular}{|c|c|c|c|c|c|c|c|c|}
\hline \multirow[t]{2}{*}{ Temperature } & \multirow[t]{2}{*}{ Admission data } & \multirow{2}{*}{$\frac{\text { Disease }}{\text { Lower UTI }}$} & \multirow{2}{*}{$\begin{array}{l}\text { Gender } \\
\mathrm{F}\end{array}$} & \multirow{2}{*}{$\frac{\mid \mathrm{IRR}}{1.002}$} & \multicolumn{3}{|l|}{$95 \% \mathrm{Cl}$} & \multirow{2}{*}{$\frac{P \text {-value }}{0.282}$} \\
\hline & & & & & 0.998 & - & 1.005 & \\
\hline & & & M & 1.004 & 0.998 & - & 1.010 & 0.205 \\
\hline & & Pyelonephritis & $\mathrm{F}$ & 1.003 & 0.994 & - & 1.012 & 0.529 \\
\hline & & & M & 1.012 & 0.990 & - & 1.035 & 0.297 \\
\hline \multirow[t]{16}{*}{ Maximum } & Inpatient & Total renal disease & $\mathrm{F}$ & 1.000 & 0.996 & - & 1.003 & 0.778 \\
\hline & & & M & 1.001 & 0.999 & - & 1.003 & 0.231 \\
\hline & & Urolithiasis & $\mathrm{F}$ & 0.992 & 0.983 & - & 1.002 & 0.139 \\
\hline & & & M & 1.001 & 0.994 & - & 1.008 & 0.788 \\
\hline & & Renal failure & $\mathrm{F}$ & 1.004 & 0.995 & - & 1.013 & 0.347 \\
\hline & & & M & 1.018 & 1.009 & - & 1.027 & $<0.001$ \\
\hline & & AKI & $\mathrm{F}$ & 1.005 & 0.995 & - & 1.014 & 0.361 \\
\hline & & & M & 1.026 & 1.014 & - & 1.037 & $<0.001$ \\
\hline & & CKD & $\mathrm{F}$ & 1.007 & 0.994 & - & 1.020 & 0.289 \\
\hline & & & M & 0.999 & 0.982 & - & 1.016 & 0.902 \\
\hline & & UTI & $\mathrm{F}$ & 0.999 & 0.996 & - & 1.003 & 0.710 \\
\hline & & & M & 1.000 & 0.998 & - & 1.003 & 0.733 \\
\hline & & Lower UTI & $\mathrm{F}$ & 0.998 & 0.994 & - & 1.002 & 0.420 \\
\hline & & & M & 1.000 & 0.998 & - & 1.003 & 0.863 \\
\hline & & Pyelonephritis & $\mathrm{F}$ & 1.003 & 0.996 & - & 1.011 & 0.400 \\
\hline & & & M & 0.994 & 0.978 & - & 1.010 & 0.470 \\
\hline \multirow[t]{16}{*}{ Minimum } & Inpatient & Total renal disease & $\mathrm{F}$ & 0.997 & 0.992 & - & 1.002 & 0.190 \\
\hline & & & M & 0.997 & 0.992 & - & 1.002 & 0.256 \\
\hline & & Urolithiasis & $\mathrm{F}$ & 0.983 & 0.969 & - & 0.997 & 0.021 \\
\hline & & & M & 0.993 & 0.985 & - & 1.002 & 0.135 \\
\hline & & Renal failure & $\mathrm{F}$ & 1.000 & 0.987 & - & 1.012 & 0.946 \\
\hline & & & M & 1.000 & 0.989 & - & 1.012 & 0.958 \\
\hline & & AKI & $\mathrm{F}$ & 0.998 & 0.984 & - & 1.012 & 0.750 \\
\hline & & & M & 0.999 & 0.986 & - & 1.012 & 0.852 \\
\hline & & CKD & $\mathrm{F}$ & 1.006 & 0.987 & - & 1.024 & 0.556 \\
\hline & & & M & 0.999 & 0.983 & - & 1.015 & 0.860 \\
\hline & & UTI & $\mathrm{F}$ & 0.998 & 0.992 & - & 1.003 & 0.415 \\
\hline & & & M & 0.995 & 0.987 & - & 1.002 & 0.183 \\
\hline & & Lower UTI & $\mathrm{F}$ & 0.998 & 0.992 & - & 1.004 & 0.494 \\
\hline & & & M & 0.997 & 0.989 & - & 1.005 & 0.437 \\
\hline & & Pyelonephritis & $\mathrm{F}$ & 0.996 & 0.985 & - & 1.006 & 0.419 \\
\hline & & & M & 0.982 & 0.959 & - & 1.006 & 0.133 \\
\hline \multirow[t]{8}{*}{ Average } & Inpatient & Total renal disease & $\mathrm{F}$ & 0.998 & 0.994 & - & 1.003 & 0.429 \\
\hline & & & M & 0.997 & 0.993 & - & 1.002 & 0.218 \\
\hline & & Urolithiasis & $\mathrm{F}$ & 0.987 & 0.974 & - & 1.000 & 0.045 \\
\hline & & & M & 0.992 & 0.984 & - & 1.000 & 0.047 \\
\hline & & Renal failure & $\mathrm{F}$ & 1.003 & 0.992 & - & 1.015 & 0.567 \\
\hline & & & M & 0.998 & 0.988 & - & 1.008 & 0.706 \\
\hline & & AKI & $\mathrm{F}$ & 1.003 & 0.990 & - & 1.016 & 0.658 \\
\hline & & & M & 0.997 & 0.985 & - & 1.009 & 0.592 \\
\hline
\end{tabular}


Table 6 Incidence rate ratios (IRRs) for renal outcomes and daily temperature stratified by gender (Continued)

\begin{tabular}{|c|c|c|c|c|c|c|c|c|}
\hline Temperature & Admission data & Disease & Gender & IRR & $95 \% \mathrm{Cl}$ & & & $P$-value \\
\hline & & CKD & $\mathrm{F}$ & 1.008 & 0.991 & - & 1.025 & 0.341 \\
\hline & & & M & 0.995 & 0.981 & - & 1.010 & 0.505 \\
\hline & & UTI & $\mathrm{F}$ & 0.998 & 0.994 & - & 1.003 & 0.533 \\
\hline & & & M & 0.996 & 0.989 & - & 1.003 & 0.271 \\
\hline & & Lower UTI & $\mathrm{F}$ & 0.998 & 0.992 & - & 1.003 & 0.400 \\
\hline & & & M & 0.997 & 0.990 & - & 1.005 & 0.458 \\
\hline & & Pyelonephritis & $\mathrm{F}$ & 1.001 & 0.991 & - & 1.011 & 0.855 \\
\hline & & & M & 0.987 & 0.966 & - & 1.009 & 0.243 \\
\hline
\end{tabular}

Estimated incidence rate ratios (IRRs) and associated 95\% confidence intervals and $P$-values for daily admissions for renal diseases for males and females separately in relation to an increase in daily maximum temperature per $1^{\circ} \mathrm{C}$ during the warm seasons (October - March) in Adelaide from 1 July 2003 to 31 March 2014. Both emergency department (ED) and inpatient admissions were included

\section{Appendix 4}

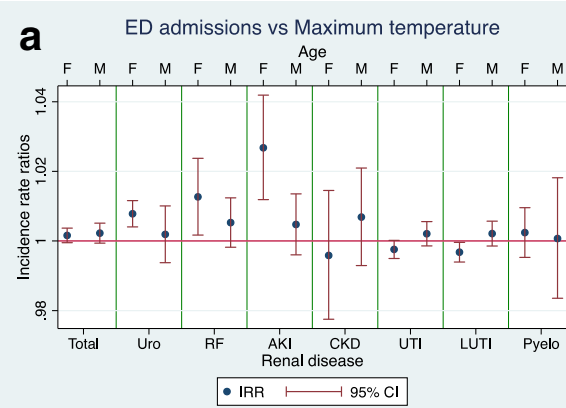

C ED admissions vs Minimum temperature

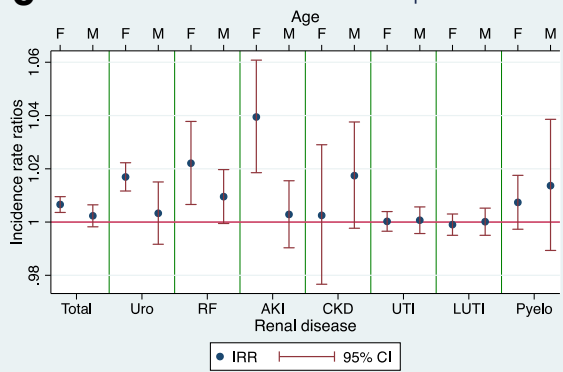

e ED admissions vs Average temperature

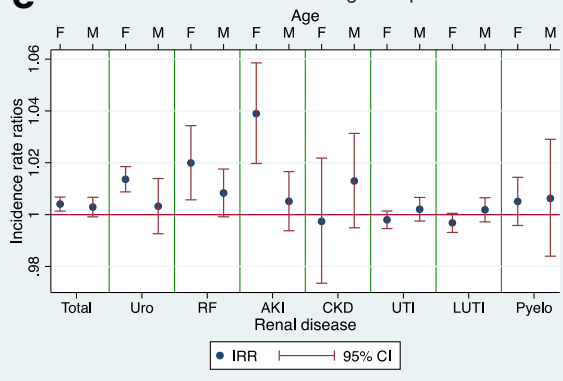

b Inpatient admissions vs Maximum temperature

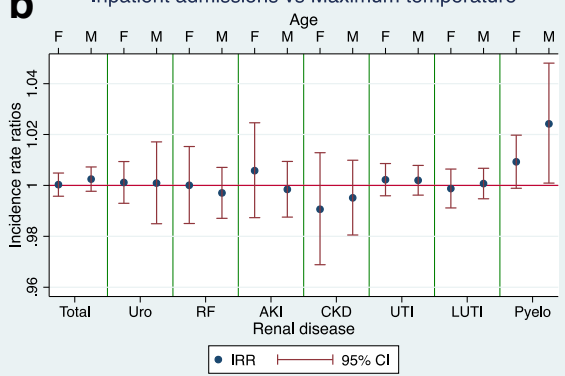

d Inpatient admissions vs Minimum temperature

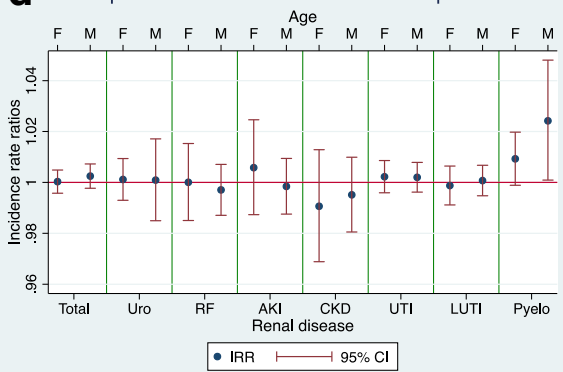

f Inpatient admissions vs Average temperature

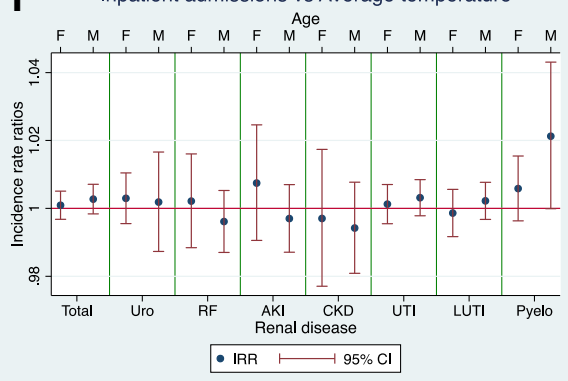

Fig. 9 Incidence rate ratios (IRRs) for renal admissions and daily temperature stratified by age ( $<65$ and $65+$ years). Graphs for incidence rate ratios (IRRs) for daily admissions for renal diseases and associated $95 \%$ confidence intervals $(95 \% \mathrm{Cl})$ in relation to daily temperature, per $1^{\circ} \mathrm{C}$, during the warm season (October - March) in Adelaide from 1 July 2003 to 31 March 2014. Results are shown for those <65 (<65) and $\geq 65$ (65+) years. Graphs (a), (c) and (e) represent emergency department $(E D)$ admissions, and graphs $(\mathbf{b}),(\mathbf{d})$ and $(\mathbf{f})$ represent inpatient admissions. The temperature measures shown are maximum ((a) and (b)), minimum ((c) and (d)) and average ((e) and (f)). The renal categories are: total renal disease (Total); urolithiasis (Uro); renal failure (RF); acute kidney injury (AKI); chronic kidney disease (CKD); urinary tract infections (UTI); lower urinary tract infections (LUTI); pyelonephritis (Pyelo) 
Table 7 Incidence rate ratios (IRRs) for renal outcomes and daily temperature stratified by age $(<65$ and $65+$ years)

\begin{tabular}{|c|c|c|c|c|c|c|c|c|}
\hline \multirow{2}{*}{$\frac{\text { Temperature }}{\text { Maximum }}$} & \multirow{2}{*}{$\begin{array}{l}\text { Admission data } \\
\text { ED }\end{array}$} & \multirow{2}{*}{$\begin{array}{l}\text { Disease } \\
\text { Total renal disease }\end{array}$} & \multirow{2}{*}{$\begin{array}{l}\text { Age } \\
65\end{array}$} & \multirow{2}{*}{$\frac{\mathrm{IRR}}{1.002}$} & \multicolumn{3}{|c|}{$95 \% \mathrm{Cl}$} & \multirow{2}{*}{$\frac{P \text {-value }}{0.137}$} \\
\hline & & & & & 0.999 & - & 1.004 & \\
\hline & & & $65+$ & 1.002 & 0.999 & - & 1.005 & 0.127 \\
\hline & & Urolithiasis & $<65$ & 1.008 & 1.004 & - & 1.012 & $<0.001$ \\
\hline & & & $65+$ & 1.002 & 0.994 & - & 1.010 & 0.650 \\
\hline & & Renal failure & $<65$ & 1.013 & 1.002 & - & 1.024 & 0.023 \\
\hline & & & $65+$ & 1.005 & 0.998 & - & 1.012 & 0.143 \\
\hline & & AKI & $<65$ & 1.027 & 1.012 & - & 1.042 & 0.000 \\
\hline & & & $65+$ & 1.005 & 0.996 & - & 1.014 & 0.287 \\
\hline & & CKD & $<65$ & 0.996 & 0.978 & - & 1.015 & 0.660 \\
\hline & & & $65+$ & 1.007 & 0.993 & - & 1.021 & 0.336 \\
\hline & & UTI & $<65$ & 0.998 & 0.995 & - & 1.000 & 0.067 \\
\hline & & & $65+$ & 1.002 & 0.999 & - & 1.006 & 0.245 \\
\hline & & Lower UTI & $<65$ & 0.997 & 0.994 & - & 1.000 & 0.025 \\
\hline & & & $65+$ & 1.002 & 0.999 & - & 1.006 & 0.243 \\
\hline & & Pyelonephritis & $<65$ & 1.002 & 0.995 & - & 1.010 & 0.510 \\
\hline & & & $65+$ & 1.001 & 0.984 & - & 1.018 & 0.937 \\
\hline \multirow[t]{16}{*}{ Minimum } & ED & Total renal disease & $<65$ & 1.007 & 1.004 & - & 1.010 & $<0.001$ \\
\hline & & & $65+$ & 1.002 & 0.998 & - & 1.006 & 0.268 \\
\hline & & Urolithiasis & $<65$ & 1.017 & 1.012 & - & 1.022 & $<0.001$ \\
\hline & & & $65+$ & 1.003 & 0.992 & - & 1.015 & 0.581 \\
\hline & & Renal failure & $<65$ & 1.022 & 1.007 & - & 1.038 & 0.005 \\
\hline & & & $65+$ & 1.010 & 0.999 & - & 1.020 & 0.064 \\
\hline & & AKI & $<65$ & 1.039 & 1.019 & - & 1.061 & $<0.001$ \\
\hline & & & $65+$ & 1.003 & 0.990 & - & 1.015 & 0.658 \\
\hline & & CKD & $<65$ & 1.002 & 0.977 & - & 1.029 & 0.852 \\
\hline & & & $65+$ & 1.017 & 0.998 & - & 1.038 & 0.084 \\
\hline & & UTI & $<65$ & 1.000 & 0.997 & - & 1.004 & 0.905 \\
\hline & & & $65+$ & 1.001 & 0.996 & - & 1.006 & 0.792 \\
\hline & & Lower UTI & $<65$ & 0.999 & 0.995 & - & 1.003 & 0.629 \\
\hline & & & $65+$ & 1.000 & 0.995 & - & 1.005 & 0.968 \\
\hline & & Pyelonephritis & $<65$ & 1.007 & 0.997 & - & 1.018 & 0.152 \\
\hline & & & $65+$ & 1.014 & 0.989 & - & 1.039 & 0.274 \\
\hline \multirow[t]{12}{*}{ Average } & ED & Total renal disease & $<65$ & 1.004 & 1.001 & - & 1.007 & 0.003 \\
\hline & & & $65+$ & 1.003 & 0.999 & - & 1.007 & 0.131 \\
\hline & & Urolithiasis & $<65$ & 1.014 & 1.009 & - & 1.019 & $<0.001$ \\
\hline & & & $65+$ & 1.003 & 0.993 & - & 1.014 & 0.555 \\
\hline & & Renal failure & $<65$ & 1.020 & 1.006 & - & 1.034 & 0.006 \\
\hline & & & $65+$ & 1.008 & 0.999 & - & 1.018 & 0.076 \\
\hline & & AKI & $<65$ & 1.039 & 1.020 & - & 1.059 & $<0.001$ \\
\hline & & & $65+$ & 1.005 & 0.994 & - & 1.017 & 0.379 \\
\hline & & CKD & $<65$ & 0.997 & 0.974 & - & 1.022 & 0.831 \\
\hline & & & $65+$ & 1.013 & 0.995 & - & 1.031 & 0.160 \\
\hline & & UTI & $<65$ & 0.998 & 0.995 & - & 1.001 & 0.246 \\
\hline & & & $65+$ & 1.002 & 0.998 & - & 1.007 & 0.377 \\
\hline
\end{tabular}


Table 7 Incidence rate ratios (IRRs) for renal outcomes and daily temperature stratified by age ( $<65$ and $65+$ years) (Continued)

\begin{tabular}{|c|c|c|c|c|c|c|c|c|}
\hline \multirow[t]{2}{*}{ Temperature } & \multirow[t]{2}{*}{ Admission data } & \multirow{2}{*}{$\frac{\text { Disease }}{\text { Lower UTI }}$} & \multirow{2}{*}{$\begin{array}{l}\text { Age } \\
<65\end{array}$} & \multirow{2}{*}{$\begin{array}{l}\text { IRR } \\
0.997\end{array}$} & \multicolumn{3}{|l|}{$95 \% \mathrm{Cl}$} & \multirow{2}{*}{$\frac{P \text {-value }}{0.089}$} \\
\hline & & & & & 0.993 & - & 1.000 & \\
\hline & & & $65+$ & 1.002 & 0.997 & - & 1.007 & 0.431 \\
\hline & & Pyelonephritis & $<65$ & 1.005 & 0.996 & - & 1.014 & 0.285 \\
\hline & & & $65+$ & 1.006 & 0.984 & - & 1.029 & 0.587 \\
\hline \multirow[t]{16}{*}{ Maximum } & Inpatient & Total renal disease & $<65$ & 1.001 & 0.998 & - & 1.004 & 0.587 \\
\hline & & & $65+$ & 1.002 & 0.999 & - & 1.005 & 0.229 \\
\hline & & Urolithiasis & $<65$ & 1.003 & 0.997 & - & 1.009 & 0.334 \\
\hline & & & $65+$ & 1.002 & 0.991 & - & 1.013 & 0.754 \\
\hline & & Renal failure & $<65$ & 1.002 & 0.992 & - & 1.013 & 0.657 \\
\hline & & & $65+$ & 0.997 & 0.990 & - & 1.004 & 0.388 \\
\hline & & AKI & $<65$ & 1.006 & 0.993 & - & 1.019 & 0.389 \\
\hline & & & $65+$ & 0.997 & 0.990 & - & 1.005 & 0.479 \\
\hline & & CKD & $<65$ & 1.001 & 0.986 & - & 1.017 & 0.881 \\
\hline & & & $65+$ & 0.996 & 0.986 & - & 1.006 & 0.419 \\
\hline & & UTI & $<65$ & 1.000 & 0.996 & - & 1.005 & 0.887 \\
\hline & & & $65+$ & 1.003 & 0.999 & - & 1.007 & 0.185 \\
\hline & & Lower UTI & $<65$ & 0.999 & 0.994 & - & 1.004 & 0.693 \\
\hline & & & $65+$ & 1.002 & 0.998 & - & 1.006 & 0.282 \\
\hline & & Pyelonephritis & $<65$ & 1.002 & 0.995 & - & 1.010 & 0.540 \\
\hline & & & $65+$ & 1.013 & 0.997 & - & 1.030 & 0.115 \\
\hline \multirow[t]{16}{*}{ Minimum } & Inpatient & Total renal disease & $<65$ & 1.000 & 0.996 & - & 1.005 & 0.896 \\
\hline & & & $65+$ & 1.002 & 0.998 & - & 1.007 & 0.309 \\
\hline & & Urolithiasis & $<65$ & 1.001 & 0.993 & - & 1.009 & 0.782 \\
\hline & & & $65+$ & 1.001 & 0.985 & - & 1.017 & 0.912 \\
\hline & & Renal failure & $<65$ & 1.000 & 0.985 & - & 1.015 & 0.995 \\
\hline & & & $65+$ & 0.997 & 0.987 & - & 1.007 & 0.563 \\
\hline & & AKI & $<65$ & 1.006 & 0.987 & - & 1.025 & 0.540 \\
\hline & & & $65+$ & 0.998 & 0.988 & - & 1.009 & 0.780 \\
\hline & & CKD & $<65$ & 0.991 & 0.969 & - & 1.013 & 0.406 \\
\hline & & & $65+$ & 0.995 & 0.981 & - & 1.010 & 0.516 \\
\hline & & UTI & $<65$ & 1.002 & 0.996 & - & 1.009 & 0.489 \\
\hline & & & $65+$ & 1.002 & 0.996 & - & 1.008 & 0.499 \\
\hline & & Lower UTI & $<65$ & 0.999 & 0.991 & - & 1.006 & 0.749 \\
\hline & & & $65+$ & 1.001 & 0.995 & - & 1.007 & 0.812 \\
\hline & & Pyelonephritis & $<65$ & 1.009 & 0.999 & - & 1.020 & 0.080 \\
\hline & & & $65+$ & 1.024 & 1.001 & - & 1.048 & 0.042 \\
\hline \multirow[t]{8}{*}{ Average } & Inpatient & Total renal disease & $<65$ & 1.001 & 0.997 & - & 1.005 & 0.667 \\
\hline & & & $65+$ & 1.003 & 0.998 & - & 1.007 & 0.222 \\
\hline & & Urolithiasis & $<65$ & 1.003 & 0.996 & - & 1.010 & 0.439 \\
\hline & & & $65+$ & 1.002 & 0.987 & - & 1.017 & 0.805 \\
\hline & & Renal failure & $<65$ & 1.002 & 0.988 & - & 1.016 & 0.762 \\
\hline & & & $65+$ & 0.996 & 0.987 & - & 1.005 & 0.404 \\
\hline & & AKI & $<65$ & 1.007 & 0.991 & - & 1.025 & 0.390 \\
\hline & & & $65+$ & 0.997 & 0.987 & - & 1.007 & 0.554 \\
\hline
\end{tabular}


Table 7 Incidence rate ratios (IRRs) for renal outcomes and daily temperature stratified by age (<65 and 65+ years) (Continued)

\begin{tabular}{|c|c|c|c|c|c|c|c|c|}
\hline \multirow[t]{2}{*}{ Temperature } & \multirow[t]{2}{*}{ Admission data } & \multirow{2}{*}{$\begin{array}{l}\text { Disease } \\
\text { CKD }\end{array}$} & \multirow{2}{*}{$\begin{array}{l}\text { Age } \\
<65\end{array}$} & \multirow{2}{*}{$\begin{array}{l}\text { IRR } \\
0.997\end{array}$} & \multicolumn{3}{|c|}{$95 \% \mathrm{Cl}$} & \multirow{2}{*}{$\begin{array}{l}P \text {-value } \\
0.772\end{array}$} \\
\hline & & & & & 0.977 & - & 1.017 & \\
\hline & & & $65+$ & 0.994 & 0.981 & - & 1.008 & 0.399 \\
\hline & & UTI & $<65$ & 1.001 & 0.995 & - & 1.007 & 0.675 \\
\hline & & & $65+$ & 1.003 & 0.998 & - & 1.008 & 0.249 \\
\hline & & Lower UTI & $<65$ & 0.999 & 0.992 & - & 1.006 & 0.695 \\
\hline & & & $65+$ & 1.002 & 0.997 & - & 1.008 & 0.429 \\
\hline & & Pyelonephritis & $<65$ & 1.006 & 0.996 & - & 1.015 & 0.231 \\
\hline & & & $65+$ & 1.021 & 1.000 & - & 1.043 & 0.051 \\
\hline
\end{tabular}

Estimated incidence rate ratios (IRRs) and associated 95\% confidence intervals and $P$-values for daily admissions for renal diseases in relation to an increase in daily maximum temperature per $1{ }^{\circ} \mathrm{C}$ during the warm seasons (October - March) in Adelaide from 1 July 2003 to 31 March 2014 . Patients are separated into two groups: one for patients aged $<65$ years old, another for patients aged $\geq 65$ years old. Both emergency department (ED) and inpatient admissions were included

\section{Abbreviations}

AKI: Acute kidney injury; CKD: Chronic kidney disease; ECF: Extracellular fluid; ED: Emergency department; ICD-10: International Classification of Diseases, 10th revision; IRR: Incidence rate ratio; LUTIs: Lower urinary tract infections; NB: Negative binomial; SA: South Australian; USA: United States of America; UTIs: Urinary tract infections

\section{Acknowledgments}

We acknowledge the South Australian Department of Health for providing hospital admissions data and the Australian Bureau of Meteorology for providing climate data. We also acknowledge Mr. Graeme Tucker and Ms. Anh-Minh Nguyen for their advice on statistical analysis and Dr. Alana Hansen for her assistance and suggestions.

\section{Funding}

Not applicable.

\section{Availability of data and materials}

Daily maximum and minimum climate data was obtained from the Bureau of Meteorology from a monitoring station in Kent Town (station number 023090) [37]. It can be freely accessed online at http://www.bom.gov.au/ climate/data/stations/.

Hospital inpatient and ED admissions data for a range of ICD-10 codes were acquired from the South Australian Department of Health. To protect patient confidentiality, the data provided was aggregated and de-identified and is not publically available.

\section{Authors' contributions}

MB was responsible for the statistical analysis and report writing. PB oversaw the project. MN was involved with the methodology of the project and supervised the statistical analysis. SW contributed to the quantitative analysis of seasonal trends in renal hospital admissions. SM oversaw the project from a renal disease perspective. All authors contributed to the final report write-up. All authors read and approved the final manuscript.

\section{Ethics approval and consent to participate}

Ethics approval for this study was obtained from the University of Adelaide Human Research Ethics Committee (No. HREC14/SAH/192) and the South Australian Department for Health and Ageing.

\section{Consent for publication}

$$
\text { Not applicable. }
$$

\section{Competing interests}

The authors declare they have no actual or potential competing interests.

\section{Publisher's Note}

Springer Nature remains neutral with regard to jurisdictional claims in published maps and institutional affiliations.

\section{Author details}

${ }^{1}$ School of Public Health, University of Adelaide, Adelaide, South Australia 5005, Australia. ${ }^{2}$ SA Health, Government of South Australia, Adelaide, South Australia, Australia. ${ }^{3}$ The Central Northern Renal and Transplantation Service, Royal Adelaide Hospital, Adelaide, South Australia, Australia.

Received: 20 June 2017 Accepted: 12 October 2017

Published online: 27 October 2017

\section{References}

1. Ostro B, Rauch S, Green R, Malig B, Basu R. The effects of temperature and use of air conditioning on hospitalizations. Am J Epidemiol. 2010;172(9):1053-61.

2. Vaneckova P, Hart MA, Beggs PJ, de Dear RJ. Synoptic analysis of heatrelated mortality in Sydney, Australia, 1993-2001. Int J Biometeorol. 2008; 52(6):439-51.

3. Bobb JF, Obermeyer Z, Wang Y, Dominici F. Cause-specific risk of hospital admission related to extreme heat in older adults. JAMA. 2014:312(24):2659-67.

4. Wilson LA, Morgan GG, Hanigan IC, Johnston FH, Abu-Rayya H, Broome R, Gaskin C, Jalaludin B. The impact of heat on mortality and morbidity in the greater metropolitan Sydney region: a case crossover analysis. Environ Health. 2013:12:98.

5. Luo $H$, Turner LR, Hurst $C$, Mai H, Zhang $Y$, Tong S. Exposure to ambient heat and urolithiasis among outdoor workers in Guangzhou, China. Sci Total Environ. 2014;472:1130-6.

6. Lujan M, Sanchez MT, Turo J, Pascual C, Chiva V, Martin C, Torres J. Climate and epidemiological characteristics of renal colic attendances in an urban setting in Spain. Actas Urol Esp. 2011;35(8):481-6.

7. Woodruff RE, McMichael T, Butler C, Hales S. Action on climate change: the health risks of procrastinating. Aust N Z J Public Health. 2006;30(6):567-71.

8. Lo SS, Johnston R, Al Sameraaii A, Metcalf PA, Rice ML, Masters JG. Seasonal variation in the acute presentation of urinary calculi over 8 years in Auckland, New Zealand. BJU Int. 2010;106(1):96-101.

9. Maller CJ, Strengers Y. Housing, heat stress and health in a changing climate: promoting the adaptive capacity of vulnerable households, a suggested way forward. Health Promot Int. 2011;26(4):492-8.

10. Nitschke M, Tucker GR, Bi P. Morbidity and mortality during heatwaves in metropolitan Adelaide. Med J Aust. 2007;187(11-12):662-5.

11. Hansen A, Bi P, Ryan P, Nitschke M, Pisaniello D, Tucker G. The effect of heat waves on hospital admissions for renal disease in a temperate city of Australia. Int J Epidemiol. 2008;37(6):1359-65.

12. Williams S, Nitschke M, Sullivan T, Tucker GR, Weinstein P, Pisaniello DL, Parton KA, Bi P. Heat and health in Adelaide, South Australia: assessment of heat thresholds and temperature relationships. Sci Total Environ. 2012;414:126-33.

13. Fletcher BA, Lin S, Fitzgerald EF, Hwang SA. Association of summer temperatures with hospital admissions for renal diseases in New York state: a case-crossover study. Am J Epidemiol. 2012;175(9):907-16.

14. Fakheri RJ, Goldfarb DS. Ambient temperature as a contributor to kidney stone formation: implications of global warming. Kidney Int. 2011;79(11):1178-85.

15. SES TC, Grundstein AJ, Winquist A, Chang HH. Time-series analysis of heat waves and emergency department visits in Atlanta, 1993 to 2012. Environ Health Perspect. 2017;125(5):057009. 
16. Hansen A, Bi P, Nitschke M, Pisaniello D, Newbury J, Kitson A. Older persons and heat-susceptibility: the role of health promotion in a changing climate. Health Promot J Austr. 2011;22 Spec No:S17-20.

17. Knowlton K, Rotkin-Ellman M, King G, Margolis HG, Smith D, Solomon G, Trent R, English P. The 2006 California heat wave: impacts on hospitalizations and emergency department visits. Environ Health Perspect. 2009;117(1):61-7.

18. Zhang Y, Nitschke M, Bi P. Risk factors for direct heat-related hospitalization during the 2009 Adelaide heatwavee: a case crossover study. Sci Total Environ. 2013;442:1-5.

19. Khalaj B, Lloyd G, Sheppeard V, Dear K. The health impacts of heat waves in five regions of new South Wales, Australia: a case-only analysis. Int Arch Occup Environ Health. 2010;83(7):833-42.

20. Vupputuri S. History of kidney stones as a possible risk factor for chronic kidney disease. Ann Epidemiol. 2004;14(3):222-8.

21. Rule AD, Krambeck AE, Lieske JC. Chronic kidney disease in kidney stone formers. Clin J Am Soc Nephrol. 2011;6(8):2069-75.

22. Park HK, Bae SR, Kim SE, Choi WS, Paick SH, Ho K, Kim HG, Lho YS. The effect of climate variability on urinary stone attacks: increased incidence associated with temperature over 18 degrees C: a population-based study Urolithiasis. 2015;43(1):89-94.

23. Sirohi M, Katz BF, Moreira DM, Dinlenc C. Monthly variations in urolithiasis presentations and their association with meteorologic factors in new York City. J Endourol. 2014;28(5):599-604.

24. Kale SS, Ghole VS, Pawar NJ, Jagtap DV. Inter-annual variability of urolithiasis epidemic from semi-arid part of Deccan Volcanic Province, India: climatic and hydrogeochemical perspectives. Int J Environ Health Res. 2014;24(3):278-89.

25. Tasian GE, Pulido JE, Gasparrini A, Saigal CS, Horton BP, Landis JR, Madison $\mathrm{R}$, Keren R. Urologic diseases in America P: daily mean temperature and clinical kidney stone presentation in five U.S. metropolitan areas: a timeseries analysis. Environ Health Perspect. 2014;122(10):1081-7.

26. Chauhan V, Eskin B, Allegra JR, Cochrane DG. Effect of season, age, and gender on renal colic incidence. Am J Emerg Med. 2004;22(7):560-3.

27. Pincus $\mathrm{S}$, Macbean $\mathrm{C}$, Taylor $\mathrm{D}$. The effects of temperature, age and sex on presentations of renal colic in Melbourne, Australia. Eur J Emerg Med. 2010; 17(6):328-31.

28. Tiu A, Tang V, Gubicak S, Knight $P$, Haxhimolla $H$. Seasonal variation of acute urolithiasis at an Australian tertiary hospital. Australas Med J. 2010;3(13):851-4.

29. Evans K, Costabile RA. Time to development of symptomatic urinary calculi in a high risk environment. J Urol. 2005;173(3):858-61.

30. Larrieu S, Carcaillon L, Lefranc A, Helmer C, Dartigues JF, Tavernier B, Ledrans M, Filleul L. Factors associated with morbidity during the 2003 heat wave in two population-based cohorts of elderly subjects: PAQUID and three City. Eur J Epidemiol. 2008;23(4):295-302

31. Brikowski TH, Lotan Y, Pearle MS. Climate-related increase in the prevalence of urolithiasis in the United States. Proc Natl Acad Sci U S A. 2008;105(28):9841-6.

32. Alexander LV, Arblaster JM. Assessing trends in observed and modelled climate extremes over Australia in relation to future projections. Int J Climatol. 2009; 29(3):417-35.

33. Tong S, Wang XY, FitzGerald G, McRae D, Neville G, Tippett V, Aitken P, Verrall K. Development of health risk-based metrics for defining a heatwave: a time series study in Brisbane, Australia. BMC public health. 2014;14:435.

34. Regional Population Growth, Australia, 2015-16 [http://www.abs.gov.au/ AUSSTATS/abs@.nsf/DetailsPage/3218.02015-16?OpenDocument\&tabname= Summary\&prodno=3218.0\&issue=2015-16\&num=\&view=]. Accessed 18 Apr 2017.

35. Area of Australia - States and Territories [http://www.ga.gov.au/scientific-topics/ geographic-information/dimensions/area-of-australia-states-and-territories]. Accessed 9 Apr 2015.

36. Griffin T, McCaskill M. Atlas of South Australia. Adelaide: South Australian Government Printing Division; 1986.

37. Government BoMA. Weather Station directory. 2017. http://www.bom.gov. au/climate/data/stations/. Accessed 18 June 2017.

38. Annual climate statement 2015 [http://www.bom.gov.au/climate/current/ annual/aus/2015/]. Accessed 11 Sept 2016.

39. Climate change information for Australia [http//www.csiro.au/en/Research/OandA Areas/Oceans-and-climate/Climate-change-information]. Accessed 11 Sept 2016.

40. About Air Temperature Data [http://www.bom.gov.au/climate/cdo/about/ about-airtemp-data.shtml]. Accessed 15 Aug 2016.

41. Lotan Y, Daudon M, Bruyere F, Talaska G, Strippoli G, Johnson RJ, Tack I. Impact of fluid intake in the prevention of urinary system diseases: a brief review. Curr Opin Nephrol Hypertens. 2013;22(Suppl 1):S1-10.
42. Hajat S, Kovats RS, Lachowycz K. Heat-related and cold-related deaths in England and Wales: who is at risk? Occup Environ Med. 2007;64(2):93-100.

43. Nitschke M, Tucker GR, Hansen AL, Williams S, Zhang Y, Bi P. Impact of two recent extreme heat episodes on morbidity and mortality in Adelaide, South Australia: a case-series analysis. Environ Health. 2011;10:42.

44. Bhaskaran K, Gasparrini A, Hajat S, Smeeth L, Armstrong B. Time series regression studies in environmental epidemiology. Int J Epidemiol. 2013; 42(4):1187-95

45. Strippoli GF, Craig JC, Rochtchina E, Flood VM, Wang JJ, Mitchell P. Fluid and nutrient intake and risk of chronic kidney disease. Nephrology. 2011; 16(3):326-34.

46. Lameire NH, Bagga A, Cruz D, De Maeseneer J, Endre Z, Kellum JA, Liu KD Mehta RL, Pannu N, Van Biesen W, et al. Acute kidney injury: an increasing global concern. Lancet. 2013;382(9887):170-9.

47. Eisner BH, Sheth S, Herrick B, Pais VM Jr, Sawyer M, Miller N, Hurd KJ, Humphreys MR. The effects of ambient temperature, humidity and season of year on urine composition in patients with nephrolithiasis. BJU Int. 2012; 110(11 Pt C):E1014-7.

48. Borissova A, Goltz GE, Kavanagh JP, Wilkins TA. Reverse engineering the kidney: modelling calcium oxalate monohydrate crystallization in the nephron. Med Biol Eng Comput. 2010;48(7):649-59.

49. Wang CJ, Grantham JJ, Wetmore JB. The medicinal use of water in rena disease. Kidney Int. 2013:84(1):45-53.

50. Lafontan M. H4H - hydration for health. Obes Facts. 2014;7(Suppl 2):1-5.

51. Clark WF, Sontrop JM, Macnab JJ, Suri RS, Moist L, Salvadori M, Garg AX. Urine volume and change in estimated GFR in a community-based cohort study. Clin J Am Soc Nephrol. 2011;6(11):2634-41.

52. Torres VE. Vasopressin in chronic kidney disease: an elephant in the room? Kidney Int. 2009;76(9):925-8.

53. Abdel-Halim RE. Urolithiasis in adults. Clinical and biochemical aspects. Saudi Med J. 2005;26(5):705-13.

54. Stafoggia M, Forastiere F, Agostini D, Biggeri A, Bisanti L, Cadum E, Caranci N, De' Donato F, De Lisio S, De Maria M, et al. Vulnerability to heat-related mortality: a multicity, population-based, case-crossover analysis. Epidemiology. 2006;17(3):315-23.

55. Basu R. High ambient temperature and mortality: a review of epidemiologic studies from 2001 to 2008. Environ Health. 2009:8:40.

56. Tong S, Wang XY, Barnett AG. Assessment of heat-related health impacts in Brisbane, Australia: comparison of different heatwave definitions. PLoS One. 2010;5(8):e12155.

57. Williams S, Nitschke M, Tucker G, Bi P. Extreme heat arrangements in South Australia: an assessment of trigger temperatures. Health Promot J Austr. 2011;22 Spec No:S21-7.

58. Australia GoS: SA health extreme heat strategy. 2016.

59. Wang HE, Muntner P, Chertow GM, Warnock DG. Acute kidney injury and mortality in hospitalized patients. Am J Nephrol. 2012;35(4):349-55.

60. Loughnan ME, Carroll M, Tapper N. Learning from our older people: pilot study findings on responding to heat. Australas J Ageing. 2014;33(4):271-7.

61. Mayner L, Arbon P, Usher K. Emergency department patient presentations during the 2009 heatwaves in Adelaide. Collegian. 2010;17(4):175-82.

62. Reid CE, O'Neill MS, Gronlund CJ, Brines SJ, Brown DG, Diez-Roux AV, Schwartz J. Mapping community determinants of heat vulnerability. Environ Health Perspect. 2009;117(11):1730-6.

63. Tan J, Zheng Y, Song G, Kalkstein LS, Kalkstein AJ, Tang X. Heat wave impacts on mortality in shanghai, 1998 and 2003. Int J Biometeorol. 2007; 51(3):193-200

64. Cervellin G, Comelli I, Comelli D, Meschi T, Lippi G, Borghi L. Mean temperature and humidity variations, along with patient age, predict the number of visits for renal colic in a large urban emergency department: results of a 9-year survey. J Epidemiol Glob Health. 2012;2(1):31-8.

65. Ranucci M, Castelvecchio S, La Rovere MT. Renal function changes and seasonal temperature in patients undergoing cardiac surgery. Chronobiol Int. 2014;31(2):175-81.

66. Armstrong B, Gasparrini A, Hajat S. Estimating mortality displacement during and after heat waves. Am J Epidemiol. 2014;179(12):1405-6.

67. Saha MV, Davis RE, Hondula DM. Mortality displacement as a function of heat event strength in 7 US cities. Am J Epidemiol. 2014;179(4):467-74.

68. Kenny GP, Yardley J, Brown C, Sigal RJ, Jay O. Heat stress in older individuals and patients with common chronic diseases. CMAJ. 2010;182(10):1053-60.

69. Schwartz J. Who is sensitive to extremes of temperature? A case-only analysis. Epidemiology. 2005;16(1):67-72. 
70. Peiffer JJ, Abbiss CR. Thermal stress in north western Australian iron ore mining staff. Ann Occup Hyg. 2013;57(4):519-27.

71. Xiang J, Bi P, Pisaniello D, Hansen A. The impact of heatwaves on workers' health and safety in Adelaide, South Australia. Environ Res. 2014;133:90-5.

72. Belshaw C. Preventing heat stroke in Australian communities. Aust Nurs J. 2009;16(7):28-31.

73. Luber G, McGeehin M. Climate change and extreme heat events. Am J Prev Med. 2008;35(5):429-35.

74. Hansen A, Bi P, Nitschke M, Ryan P, Pisaniello D, Tucker G. The effect of heat waves on mental health in a temperate Australian city. Environ Health Perspect. 2008;116(10):1369-75.

75. Flynn A, McGreevy C, Mulkerrin EC. Why do older patients die in a heatwave? QJM. 2005:98(3):227-9.

76. Conti S, Masocco M, Meli P, Minelli G, Palummeri E, Solimini R, Toccaceli V, Vichi M. General and specific mortality among the elderly during the 2003 heat wave in Genoa (Italy). Environ Res. 2007;103(2):267-74.

77. Goldney RD, Fisher L. Use of prescribed medications in a south Australian community sample. Med J Aust. 2005;183(5):251-3.

78. Nitschke M, Tucker G, Hansen A, Williams S, Zhang Y, Bi P. Evaluation of a heat warning system in Adelaide, South Australia, using case-series analysis. BMJ Open. 2016;6(7):e012125.

\section{Submit your next manuscript to BioMed Central} and we will help you at every step:

- We accept pre-submission inquiries

- Our selector tool helps you to find the most relevant journal

- We provide round the clock customer support

- Convenient online submission

- Thorough peer review

- Inclusion in PubMed and all major indexing services

- Maximum visibility for your research

Submit your manuscript at www.biomedcentral.com/submit 